\title{
Dynamic Inconsistencies: Counterfactual Implications of a Class of Rational Expectations Models
}

\author{
Arturo Estrella* \\ Federal Reserve Bank of New York \\ Jeffrey C. Fuhrer ${ }^{* *}$ \\ Federal Reserve Bank of Boston
}

December 1998

\begin{abstract}
A number of recent papers have developed dynamic macroeconomic models that incorporate rational expectations and optimizing foundations. While the theoretical motivation behind these models is sound, the dynamic implications of many of the specifications that assume rational expectations and optimizing behavior can be seriously at odds with the data, for both inflation and real-side variables. In a nutshell, the models imply that inflation or real spending "jump" in response to shocks, in contradiction to a host of empirical evidence that shows that both price and real-side variables exhibit gradual and "hump-shaped" responses to real and monetary shocks. For models that are intended for monetary policy analysis, these dynamic shortcomings should be considered quite serious. When monetary policy has only short-run effects on real variables, the inability to approximately capture the short-run responses of inflation or real variables to policy shocks makes a model unsuitable for policy analysis. This paper identifies a simple feature common to many dynamic specifications for prices and real variables that causes the problem. The paper also discusses several potential solutions to the problem, including alterations to the expectations assumption, to the order of differencing implicit in the model, and to the underlying behavioral assumptions.
\end{abstract}

${ }^{*}$ Senior Vice President, Research and Market Analysis, Federal Reserve Bank of New York, 33 Liberty Street, New York, NY 10045. E-mail: arturo.estrella@ny.frb.org.

${ }^{* *}$ Vice President and Economist, Federal Reserve Bank of Boston, 600 Atlantic Avenue, Boston, MA 02106. e-mail: Jeff.Fuhrer@bos.frb.org.

The views expressed in this paper are the authors' and do not necessarily reflect those of the Federal Reserve Banks of Boston or New York or the Federal Reserve System. 


\section{Dynamic Inconsistencies: Counterfactual Implications of a Class of Rational Expectations Models}

\section{$\underline{\text { Introduction }}$}

A number of recent papers have developed dynamic macroeconomic models that incorporate rational expectations and optimizing foundations (see, for example, Mankiw (1985), Roberts (1995), Woodford (1996), McCallum and Nelson (1998), and Rotemberg and Woodford (1997)). Both features are included in order to make the models less subject to the Lucas (1976) critique. The first feature allows agents to revise expectations in response to changes in the systematic behavior of other agents in the model (with policymakers the leading example), in contrast to simple adaptive or autoregressive expectations schema. The second hopes to put the model on a more structural--and, hopefully, more stable--foundation by deriving the behavioral relationships in the model from "deeper" motives such as utility or profit maximization, in contrast to the less-constrained, reduced-form distributed lag relationships of earlier models.

While the theoretical motivation behind these models is sound, the dynamic implications of many of the specifications that assume rational expectations and optimizing behavior are often seriously at odds with the data. These "dynamic inconsistencies" between theory and data arise in the models for both prices (or inflation) and real-side variables.

To take a leading example, many standard specifications of aggregate prices build in the expected (and data-consistent) positive correlation between the level of inflation and real output, but imply a counterintuitive and counterfactual negative correlation between the expected change in inflation and real output. The dynamic implication of these opposite-signed correlations is that, in response to a negative real output shock, the level of inflation will fall, while the change in inflation will always be positive. This can only occur if inflation jumps down immediately in response to the shock, and subsequently rises back to its new lower equilibrium from below.

The problem with this example, and with the others discussed below, is that a host of empirical evidence suggests that both price and real-side variables exhibit gradual and "humpshaped" responses to real and monetary shocks. Neither inflation nor real output or consumption appears to jump in response to shocks. Previous work has shown that, for inflation and 
consumption expenditures, this gradual response is an extremely robust feature of the data (Fuhrer and Moore 1995, Fuhrer 1998). Standard forward-looking specifications with explicit rational expectations are incapable of replicating this important feature of the data.

In models that are intended for use in monetary policy analysis, these dynamic shortcomings should be considered quite serious. There is broad consensus that monetary policy has only short-run effects on real variables, so that the inability of these models to reflect the short-run responses of real variables to policy shocks makes them unsuitable for policy analysis.

In this paper, we present some empirical evidence of the counterfactual dynamic implications of the class of models on which we focus, and we identify a simple feature common to many dynamic specifications for prices and real variables to which the cause of the empirical problems may be traced. The paper also discusses potential solutions to the problem, including alterations to the expectations assumption, to the order of differencing in the model, and to the underlying utility function for consumers. Section 1 illustrates the problem by contrasting the dynamic implications of a recent model that has the features in question with those of one that does not. Section 2 examines the problem in its general form. Section 3 discusses various examples of the problem in the recent literature. Section 4 considers extensions to the general form of Section 2, some of which may improve the empirical dynamics. Section 5 examines the effects of interest rate smoothing on the dynamics through some simple simulation exercises, and Section 6 concludes.

\section{Empirical Evidence of Dynamic Inconsistencies}

In this section, we present an example of a model that illustrates the main point of this paper (McCallum and Nelson 1998). The model is based on explicit optimization and thus has a solid theoretical basis. However, the model incorporates forward-looking rational expectations in such a way that, as we later show, counterfactual empirical implications must result. We contrast the empirical performance of that model with that of a backward-looking model (Rudebusch and Svensson 1998), which is essentially a somewhat restricted vector autoregression (VAR). To provide a context for the comparison of these two non-nested approaches, we also present results for an unconstrained VAR that nests the two constrained models. 
The two illustrative models were developed with similar objectives: they were designed to test a variety of policy reaction functions of the Taylor (1993) variety. These rules generally model a short-term interest rate in terms of forward- or backward-looking reactions to inflation and unemployment, as well as lags of the interest rate itself. Each of the models we examine consists of the reaction function equation, plus inflation and output equations.

Both models exploit the same robust empirical regularities, namely, relationships between inflation and an output gap (Phillips curve) and between output and real interest rates (IS curve). However, differences in the form of the models, specifically the inclusion or exclusion of explicit forward-looking rational expectations, lead to dramatically different dynamic behavior.

Since neither of the two base models contains a fixed policy rule, we use in both cases a policy reaction estimated by Clarida, Gali and Gertler (1998) for the United States over the period from Q4 1979 to Q4 1996. The policy rule was estimated in a multi-equation context in which both the Phillips and IS curves contained forward-looking rational expectations, like the McCallum-Nelson (1998) model.

We use the following strategy in the empirical illustrations. First, we specify each model as estimated in the papers cited. Re-estimating the models using comparable data did not affect the estimates materially, so we chose to use the original authors' models. As noted, we also estimate an unrestricted VAR for use as a benchmark. Second, we use each model to generate a residual covariance matrix that is consistent with the model, given the data and the estimated parameters. Third, we calculate a series of statistics for each of the models, namely, vector autocorrelations, impulse responses and likelihood ratio statistics.

\section{A. Models}

The benchmark VAR is a standard unrestricted quarterly model that includes the four variables that play a major role in either or both the McCallum-Nelson (1998) model (MN) and the Rudebusch-Svensson (1998) model (RS). Each equation includes a constant term plus four lags of each of four variables: the output gap, inflation, the federal funds rate, and real defense expenditures. 
Potential output, which is used in the computation of the output gap (y), is defined as in the $\mathrm{MN}$ model as a simple function of hours worked. This choice is somewhat unusual, but McCallum and Nelson (1998) stress the visible differences arising in the output gap from different choices of potential output. Hence, we follow the $\mathrm{MN}$ model in order to ensure that results are not biased against it for this reason. Other output gaps were tested with only minor qualitative differences, and some of these tests are reported below.

Inflation $(\pi)$ is simply the quarterly log difference in the deflator for chain-weighted GDP. The federal funds rate $(r)$ is the quarterly average of daily nominal rates. Finally, the defense expenditures variable $(x)$ is included because it is an important instrument in the estimation of the MN model.

Turning to the specific structural models, the MN model contains a Phillips curve of the form

$$
\pi_{t}=0.99 E_{t} \pi_{t+1}+0.075 y_{t}+\eta_{t}
$$

and an IS curve

$$
y_{t}=-0.964+E_{t} y_{t+1}-0.164\left(r_{t}-E_{t} \pi_{t+1}\right)+\epsilon_{t} .
$$

We discuss briefly the derivation of these equations from an optimizing framework in Section 4, and more details are provided in McCallum and Nelson (1998).

The MN model is closed by adding the Clarida, Gali and Gertler (1998) post-1979 reaction function, which is

$$
r_{t}=0.69 r_{t-1}+0.31\left[\left(\bar{r}+1.91\left(E_{t} \pi_{t+1}-\bar{\pi}\right)+0.07 y_{t}\right]\right.
$$

where $\bar{r}$ and $\bar{\pi}$ are set so that the residuals for the reaction function equal zero on average for the post-1979 sample.

The Phillips curve in the RS model is backward looking:

$$
\pi_{t}=0.19+0.68 \pi_{t-1}-0.11 \pi_{t-2}+0.30 \pi_{t-3}+0.10 \pi_{t-4}+0.15 y_{t^{-}, 1}+\epsilon_{t}
$$


as is the IS curve:

$$
y_{t}=0.18+1.17 y_{t-1}-0.27 y_{t-2}-0.08\left(\bar{r}_{t-1}-\bar{\pi}_{t-1}\right)
$$

where $\bar{r}_{t}=1 / 4 \sum_{j=0}^{3} r_{t-j}$ and $\bar{\pi}_{t}=1 / 4 \sum_{j=0}^{3} \pi_{t-j}$. The reaction function is the same as in the MN model.

\section{B. Vector autocorrelations}

The specification of each model as described above was used to generate a set of disturbances for the equations. Given the disturbance covariance matrix derived from these estimates and the structural coefficients for the model, we can estimate a vector autocorrelation function, which contains all of the second-moment information implied by the model. ${ }^{1}$ Figure 1 presents the results of this exercise for both the VAR and the MN model and for each of the principal variables of the models. Consider a couple of interesting features of these results.

First, the solid lines in the figures on the diagonal indicate that there is substantial persistence in the data for each of the three variables. The same-variable autocorrelations from the VAR, indicated by the solid curves, are all positive over the horizons reported. In contrast, the forward-looking $\mathrm{MN}$ formulation implies almost no persistence, as evidenced by the autocorrelation for inflation and the output gap, which drop very close to zero within one quarter. The main source of persistence in the model is provided by the policy rule, as indicated by the autocorrelation of the federal funds rate in the middle panel. This property is further examined in Section 5 .

Also noteworthy are two panels that correspond roughly to the Phillips curve and IS relationships. In the upper right, we see that the correlation between inflation and the lagged output gap builds gradually to positive values over a long period. In the MN model, this correlation starts out positive, but becomes essentially zero after one quarter.

\footnotetext{
${ }^{1}$ See the Appendix in Fuhrer and Moore (1995) for computation details.
} 
In the bottom middle panel we see that in the VAR, the output gap has large and consistently negative correlations with the lagged interest rate and that these also build up over a long period. The correlation in the MN model is substantially smaller and less persistent.

The results for the RS model, presented in Figure 2, are much closer than those of the MN model to the VAR results, which are also shown in the figure for comparison. Qualitatively, it is hard to distinguish between the RS and the VAR results. Quantitatively, there is a consistent overstatement of the correlations between inflation and the lagged funds rate, and in most cases there are noticeable divergences at various points along the correlation function. Nevertheless, the patterns are very similar. This is perhaps not surprising, since the RS model is essentially an onlymoderately-constrained VAR. The results do indicate that, at least visually, the constraints imposed do no major violence to the dynamic implications of the model. More precise tests, however, do indicate some noticeable discrepancies, as we see below.

\section{Impulse responses}

Impulse response functions are frequently easier to interpret than vector autocorrelations. The cost of this intuition, however, is that we must impose some potentially arbitrary structure on the model, for instance, in the form of contemporaneous ordering of the shocks. In the analysis that follows, we adopt the ordering: inflation, funds rate, and output gap, which means that the funds rate may react contemporaneously to inflation but not to output (reflecting the contemporaneous availability of current-quarter price information, but the lagged availability of current-quarter real GDP data). Placing the funds rate at the end did not affect the results materially. With these caveats, we present impulse responses for the two models in Figures 3 and 4. Once again, VAR results are indicated as solid lines for reference purposes. All responses are 
represented as deviations from equilibrium values. Ninety percent confidence bands are indicated by the lighter dotted lines in the figures. ${ }^{2}$

In Figure 3, we see more pointedly than with the autocorrelations that the effects of shocks to the Phillips and IS curves are very transitory in the MN model, as compared with the gradual declines in the VAR. For instance, if we look at the top right panel of Figure 3, we note that the reaction of inflation to an output shock turns negative in one quarter and then remains essentially at zero. This pattern is consistent with a difference in sign between the correlation of the level of inflation and the output gap and the correlation of the change in inflation and the output gap, which we will see in the next section is an intrinsic feature of the general type of rational expectations model on which we focus in this paper. The impulse response from the VAR is a gradual build-up of the effect of the output gap, with inflation gradually declining to zero after a few (6) quarters. We see similar impulse response patterns in the reaction of inflation to an inflation shock or of the output gap to an output shock.

The sharper implications of the output responses are less favorable to the RS than the vector autocorrelations, but the RS model still outperforms the MN model on a relative basis. For instance, in Figure 4, the reactions of both inflation and the funds rate to an interest rate shock are consistently overstated, though the model captures the general shape of the response better than the MN model. The reaction of the output gap to an interest rate shock is also qualitatively similar to the VAR, but the lag in the reaction is shorter and the magnitude is lower. The short-term reaction of the funds rate to inflation is also overstated.

\section{Model Selection Criteria and Non-Nested Model Tests}

Although the results of examining the autocorrelation and impulse response functions are relatively clear and suggestive, it is desirable to apply more precise statistical tests to compare the

\footnotetext{
${ }^{2}$ The impulse responses for the VAR are computed using conventional methods. The impulse responses for the structural models are computed by obtaining the restricted reduced form consistent with the structural model under rational expectations, and then ordering and orthogonalizing the model exactly as in the VAR. The method for obtaining the restricted reduced form, which is also used in the vector autocorrelation and likelihood calculations, is detailed in Anderson and Moore (1985) and in Appendix A of Fuhrer and Moore (1995).
} 
MN and RS models. Tests of the RS model against the VAR are straightforward because RS is nested in the VAR. In a somewhat more complicated way, the MN model is also nested in the VAR, which suggests one possible strategy. We can look at likelihood ratio tests of each model against the VAR and compare the relative performance.

Thus, let $X=2\left(L_{V A R}-L_{j}\right) \sim \chi^{2}(k)$ be the likelihood ratio test statistic for model $j$ (= MN or RS) against the VAR, where $L$ is the log-likelihood of a model and $k$ is the number of restrictions in the model relative to the VAR. For these purposes, we run a three-equation VAR, dropping the defense expenditures variable for consistency. Thus, the VAR has 39 parameters, compared with 17 in the RS model and at least 4 in the MN model. ${ }^{3}$ This implies that $k=22$ for RS and we use $k=35$ as an upper bound for the MN model.

Over the period from Q4 1979 to Q2 1996, we find $X=466$ for the MN model. This is a very strong rejection of the model, with a p-value of essentially zero. Note that the one-percent significance level for $X$ with 35 degrees of freedom is 57 . The RS model is also strongly rejected. We obtain $X=70$, which corresponds to a p-value of zero to several decimal places (the onepercent level is 40). This strong rejection indicates that the RS model is far from perfect, although the rejection is not as extreme as that of the MN model.

One way of summarizing the likelihood information for the three models in a consistent framework is provided by the Akaike Information Criterion (AIC), which is based on the more general Kullback-Leibler Information Criterion. The AIC is given by the formula $-(2 / T)(L-K)$, where again $L$ is the log-likelihood of the model, $K$ is the number of free parameters, and $T$ is the number of observations. A lower value of the AIC implies better performance. As before, we use $K=4$ for MN, and obtain a lower bound for the AIC.

\begin{tabular}{cccc} 
Model & $L$ & $K$ & $A I C$ \\
\hline VAR & 1050 & 39 & -30.2
\end{tabular}

${ }^{3}$ It is straightforward to determine the number of parameters estimated in both the VAR and RS, but in for MN because of the restrictions imposed by rational expectations on MN. The numerical results, however, are very clear and not at all sensitive to the number of parameters estimated. We assume the number parameters in $\mathrm{MN}$ is simply at least four, the number in the reaction function, to obtain bounds on the results for $\mathrm{MN}$. 


$\begin{array}{lccc}\text { MN } & 817 & 4 & -24.3 \\ \text { RS } & 1015 & 17 & -29.8\end{array}$

The MN is clearly outperformed by the other two models by this measure.

Finally, we also apply statistical techniques for comparing non-nested models to test the MN and RS model against each other. Specifically, we use a two-step method suggested by Davidson and MacKinnon (1993, Section 11.3). For example, to test the MN model, we first use consistent parameter estimates to calculate the fitted values of the Phillips curve and output equations in the RS model. We then estimate a "combined model" with inflation and output equations of the form

$$
\begin{aligned}
& \pi_{t}=(1-\alpha)(R H S-P C-M N)+\alpha(\text { fitted } R H S-P C-R S)+\text { residual } \\
& y_{t}=(1-\alpha)(R H S-I S-M N)+\alpha(\text { fitted } R H S-I S-R S)+\text { residual },
\end{aligned}
$$

where the notation "RHS-PC-MN" refers to the right-hand-side of the McCallum-Nelson Phillips curve (the right hand side of equation 1), and "fitted RHS-PC-RS" refers to the fitted values for the Rudebusch-Svensson Phillips curve, obtained from applying their estimated parameter values to the data. ${ }^{4}$ We add the policy reaction function described above to the model. Davidson and MacKinnon show that a test of the hypothesis $\alpha=0$ corresponds to a test of MN relative to RS. We can also test RS against MN by reversing the roles of the two models in the above procedure. The results are as follows.

\begin{tabular}{ccc} 
Model Tested & $\hat{\alpha}$ & Standard Error \\
\hline MN & 0.509 & 0.100 \\
RS & 0.000 & 0.027
\end{tabular}

The results show that the MN model is strongly rejected in favor of the RS model, but that the RS model cannot be rejected in favor of the MN model.

\section{E. Sensitivity to potential output}

${ }^{4}$ To obtain the "fitted values" for the forward-looking McCallum-Nelson equations, we run a static simulation of the model over the data, which requires solving for the model-consistent rational expectations. 
McCallum and Nelson (1998) suggest that the choice of potential output measure can make an important difference in the estimates of these models. For this reason, we performed the analysis described above with several other measures of potential output: a measure computed by the Congressional Budget Office, a log-linear trend with a kink at 1974 Q1, a series obtained by applying the Hodrick-Prescott (HP) filter, and a series obtained by applying a band-pass filter for frequencies lower than eight years to the log first differences of read GDP. Generally, the results using these other measures were fairly close to those presented above.

Perhaps the most noticeable differences arose in connection with the HP filter, and we present the corresponding autocorrelation results in Figures 5 and 6. In this exercise, we reestimated the VAR as well as the MN and RS models using the HP series, since the latter did differ from the others sufficiently to introduce persistent deviations in the models. With reestimation, however, the results are not much different from Figures 1 and 2. One notable effect of the use of the HP filter is that the positive relationship between inflation and the lagged output gap seems more robust (solid line in upper right panel of Figure 5), as is the negative relationship between output and the lagged funds rate (solid line in bottom middle panel).

It is still true that the RS model captures the general patterns of the VAR results better than the MN model. Note, for instance, the discrepancies in Figure 5 between the VAR and the MN model in the panels corresponding to inflation versus lagged inflation, output gap versus lagged output gap, inflation versus lagged output gap, and output gap versus lagged funds rate, as pointed out in the context of Figure 1.

\section{The General Form of the Problem}

What general features of the MN model are responsible for the inconsistencies between the model and the data presented in the preceding section? We now abstract from the particular variables in that model and show that the problem may arise in a wide variety of linear rational expectations models with explicit expectations. Models used in many recent papers (see introduction and Section 3) will be seen to be special cases of this general paradigm.

The general form of the equation that produces the discrepancies is 


$$
z_{t}=E_{t} z_{t+1}+\theta x_{t}
$$

where $\theta>0$. From inspection of equation (6), we note that there is a certain form of indeterminacy in the sign of the correlation between $x$ and $z$. On one hand, (6) asserts that $z$ is positively related to $x$ and also to expected future $x$, as may be see by solving (6) forward:

$$
z_{t}=E_{t} z_{t+n}+\theta \sum_{i=0}^{n-1} E_{t} x_{t+i}
$$

On the other hand, (6) also implies that the correlation between $x_{t}$ and $\Delta z_{t+1}$ is negative. Hence, the model of (6) is unsuitable for cases in which a variable $x$ is positively correlated with both levels and changes in another variable $z$. Moreover, even when the different signs of the correlations of levels and changes are acceptable, equation (6) may require that $z$ have the flexibility to jump to levels that make the subsequent changes plausible.

Empirically, these features are illustrated by the correlations between inflation and the lagged output gap, and the corresponding impulse responses, produced by the MN model in the previous section. See, for example, the upper right-hand panels of Figures 1 (or 5) and 3.

More generally, the reasons for these features may be illustrated by calculating an explicit solution to equation (6) using methods proposed by Whiteman (1983). Suppose that $x$ is a zeromean linear covariance-stationary stochastic process with Wold representation

$$
x_{t}=\alpha(L) \epsilon_{t}
$$

where

$$
\alpha(L)=\sum_{i=0}^{\infty} \alpha_{i} L^{i}
$$

and $\sum_{i=0}^{\infty} \alpha_{i}^{2}<\infty$. We look for solutions to $z_{t}$ in the space spanned by square-summable linear combinations of the process $\left\{\epsilon_{s}: s \leq t\right\}$, so that the solution will be of the form 


$$
z_{t}=\beta(L) \epsilon_{t}
$$

where $\beta(L)$ is a one-sided lag polynomial with $\sum_{i=0}^{\infty} \beta_{i}^{2}<\infty$. Inserting (8) and (10) into (6), we obtain the functional equation

$$
(1-w) \beta(w)=\beta_{0}-\theta w \alpha(w)
$$

Solving (11) by equating the powers of $w$ on both sides of the equation, we obtain that

$$
\beta(L)=\theta \sum_{i=0}^{\infty} \sum_{j=i}^{\infty} \alpha_{j} L^{i}
$$

Equations (9) and (12) imply formally that there is a one-to-one linear transformation between the lag polynomials $\alpha(L)$ and $\beta(L)$. For instance, if $x$ is a finite order moving average process, $\operatorname{MA}(\mathrm{q})$, with $q<\infty$, then

$$
\beta(L)=\theta \sum_{i=0}^{q} \sum_{j=i}^{q} \alpha_{j} L^{i}
$$

so that $z$ is also $\operatorname{MA}(\mathrm{q})$. However, if $\alpha(L)$ is an infinite order MA polynomial, the corresponding $\beta(L)$ may not always be square-summable, as required by the solution technique.

The solution of equations (12)-(13) may be used to demonstrate in general that the signs of the correlations between $x$ and the level and change in $z$ must differ. Thus, suppose that $x$ is $\mathrm{MA}(\mathrm{q}), q \in\{0,1, \ldots, \infty\}$, and that, therefore, $z$ follows the MA(q) process given in expression (13). Then

$$
\begin{gathered}
\operatorname{cov}\left(z_{t}, x_{t}\right) \geq \frac{q+2}{2 q+2} \theta \sigma_{\epsilon}^{2} \rightarrow\left\{\begin{array}{c}
\theta \sigma_{\epsilon}^{2} \text { as } q \rightarrow 0 \\
\frac{1}{2} \theta \sigma_{\epsilon}^{2} \text { as } q \rightarrow \infty
\end{array}\right\}>0 \\
\operatorname{cov}\left(\Delta z_{t+1}, x_{t}\right) \leq-\theta \sigma_{\epsilon}^{2}<0
\end{gathered}
$$


Some interesting special cases may be examined. Suppose, for instance, that $\alpha(L)=1$, that is, $x$ is white noise. Then $\beta(L)=\theta$, and $z$ is white noise as well. Thus, a unit shock in the $x$ process at time $t$ is accompanied by a simultaneous jump of size $\theta$ in $z$. Next period, and every subsequent period thereafter, both $x$ and $z$ are expected to return to their mean of zero.

Suppose now that $x$ is $\operatorname{AR}(1)$ with lag coefficient $\rho$, with $0<|\rho|<1$. Then $\alpha_{j}=\rho^{j}$ and $\sum_{j=i}^{\infty} \alpha_{j}=\rho^{i} /(1-\rho)$, so that $z_{t}=\theta /(1-\rho) x_{t}$. Thus, $z$ also follows an AR(1) process and is in fact proportional to $x$. In this case, $E_{t} z_{t+1}-z_{t}=(\rho-1) z_{t}$, so that the opposite signs of the level of $z$ and the change in $z$ follow naturally from the dynamics of the stable univariate AR(1) process. ${ }^{5}$

The foregoing analysis is robust to various types of modifications to the model of equation (6), as we show in Section 4. For instance, the precise dating of the variable whose expectation appears in the right-hand side of (6) does not have to be one period ahead. Other future dates do not alter the conclusions in any substantive way. Changes in the viewpoint date for the expectation may be more consequential, though divergences from the basic qualitative conclusions require that the data series have unusual characteristics. More trivially, the sign of $\theta$ is arbitrary and could just as well be assumed to be negative.

Before concluding this section, we note that the inclusion of a forward-looking rational expectation in the right-hand side of (6) is a key determinant of the resulting puzzle. Suppose, on the contrary, that the model is backward-looking, for example,

${ }^{5}$ It is of some interest to note that although a stable rational expectations solution can be obtained using Whiteman's methodology, one cannot obtain a saddlepoint-stable solution to even this simplest model. The model that comprises the canonical equation (6) and the AR(1) process for $\mathrm{x}_{\mathrm{t}}$ may be shown to be equivalent to a vector $\mathrm{AR}(1)$ model $X_{t}=A X_{t-1}+\xi_{t}$, where $X=(z, x)^{\prime}$ and the state transition matrix is

$$
A=\left[\begin{array}{cc}
1 & -\theta \\
0 & \rho
\end{array}\right]
$$

which, for any value of $\theta$, has eigenvalues $\{1, \rho\}$, which lie on or inside the unit circle for $-1 \leq \rho \leq 1$. However, according to the conventional criteria (see, for example, Blanchard and Kahn (1980) and Anderson and Moore (1985)), a unique and stable solution for the model requires one left eigenvector associated with a root outside the unit circle. The models of McCallum and Nelson (1998), Rotemberg and Woodford (1997), and Svensson (1997) discussed below have saddlepoint-stable solutions. Their models differ from this simple example in that the presence of a monetary policy authority that responds to inflation and output deviations will add feedback from equation (6) into the driving process for $x$. 


$$
z_{t}=g(L) z_{t-1}+\theta^{\prime} x_{t}
$$

with $\theta^{\prime}>0$, which does not preclude that expectations may be rational and forward-looking. The same form results if the expectation in (6) is univariate backward-looking, which under some circumstances may also be rational. For instance, if

$$
E_{t} z_{t+1}=b(L) z_{t}
$$

with $b(0)<1$, then (6) assumes the form (15) with $g(L)=(b(L)-b(0)) /(L(1-b(0))$ and $\theta^{\prime}=\theta /(1-b(0))$. The ambiguity in the sign of the relationship between $x$ and the level and change in $z$ that we find in equation (6) is not exhibited by equation (15). The point here is certainly not to claim that the expectations assumed in (16) are superior in general to other forms, nor that backward-looking models are in general preferable to those with explicit expectations, but rather to observe that the explicit inclusion of unrestricted rational expectations in the right-hand side of (6) plays a key role in the sign puzzle associated with equation (6).

To summarize the main conclusion of this section, any model with the general form of equation (6) is inconsistent with robustness in the sign of the correlation between the variable $x$ and the level and change in $z$. We see in Section 1 and the appendix that this type of robustness is exhibited by the price level and output. In the next section, we explore other examples of such robustness in the context of various models proposed in the literature. Those models contain a variety of specific variables, but have the same general form as equation (6).

\section{Some Recent Examples}

A number of recent macroeconomic papers employ dynamic specifications that exhibit the features discussed above. Some, such as Roberts (1995), focus solely on the price specification; others, including Mankiw (1985) focus only on the real side; and others, such as McCallum and Nelson (1998) and Rotemberg and Woodford (1997), develop general equilibrium models that incorporate both price and real side features. This section will point out the isomorphism between the specifications used in these papers and the canonical example of Section 2. In all of the 
models, we will use the notation $\mathrm{y}_{\mathrm{t}}$ for output (usually expressed as a deviation from potential or steady-state), $R_{t}$ for the nominal interest rate, $\pi_{t}$ for inflation, and $p_{t}$ for the price level.

Interestingly, one of the most widely used consumption specifications exhibits the perverse dynamics of the canonical equation. The standard first-order condition for life-cycle consumers in the presence of a time-varying real interest rate is

$$
U^{\prime}\left(C_{t+1}\right) / U^{\prime}\left(C_{t}\right)=1 / \beta\left(1+\rho_{t+1}\right)
$$

where $C$ is the level of consumption, $\rho$ is the real (after-tax) rate of interest and $\beta$ is the subjective time rate of preference (see, for example, Mankiw (1985), pp. 354-56, Campbell and Mankiw (1991), p. 198). This equation implies that when real interest rates are expected to be high, the growth rate of marginal utility is expected to be low. For any normal specification of utility, the negative correlation between real rates and the growth in marginal utility in equation (17) implies a positive correlation between real rates and consumption growth. A host of authors have thus arrived at log-linearized first-order conditions of the form ${ }^{6}$

$$
E_{t} c_{t+1}-c_{t}=\sigma E_{t} \rho_{t+1}
$$

This equation of course implies that increases in the expected real interest rate cause expected consumption growth to rise. But equation (18) also implies that the level of consumption depends negatively on future real interest rates, which can be seen by iterating the following equation forward in time:

$$
c_{t}=E_{t} c_{t+1}-\sigma E_{t} \rho_{t+1}
$$

As in the simple example of Section 2, the standard consumption equation implies that the sign of the correlation between the real interest rate and the level of consumption is the opposite of the correlation between the real interest rate and the growth rate of consumption.

${ }^{6}$ This formulation sets the long-run growth rate of consumption to zero for convenience. 
An awkward implication of these opposite signed levels and changes correlations is that, when the real interest rate rises above its steady-state level, the level of consumption must decrease, but its change must be expected to increase. This can only be accomplished by an immediate jump downward in the level of consumption. Thus, consumption must behave as a "jump" variable. This feature is entirely consistent with the life-cycle/rational expectations consumption paradigm: consumption immediately adjusts to "news" about expected real interest rates and about expected lifetime income prospects. However, this jump behavior stands at odds with the empirical evidence (see, for example, Christiano, Eichenbaum, and Evans (1994) and Leeper, Sims, and Zha (1996)) that shows sluggish adjustment of consumption to shocks.

We have seen the empirical form of the McCallum-Nelson (1998) model in Section 1, but we provide some additional background in this section. McCallum and Nelson (1998) seek an aggregate demand specification for use in a model in which they can evaluate "operational" monetary policy rules. They begin from optimizing foundations, positing a simple utility function that is additively separable in consumption and real money balances $(M / P)$ of the form (abstracting from taste shocks)

$$
U\left(C_{t},\left(M_{t} / P_{t}\right)\right)=\sigma(\sigma-1)^{-1} C_{t}^{\frac{\sigma-1}{\sigma}}+(1-\gamma)^{-1}\left(M_{t} / P_{t}\right)^{1-\gamma}
$$

subject to a standard budget constraint. A log-linearization of the first-order conditions with respect to consumption and government bond holdings implies an "optimizing IS function"

$$
y_{t}=E_{t} y_{t+1}-\sigma\left(R_{t}-E_{t} \Delta p_{t+1}-\bar{r}\right)
$$

(see equation 3.14 in their paper), where the final expression in parentheses is the deviation of the short-term real interest rate from its equilibrium value $\bar{r}$. This equation implies the same perverse dynamics as the standard consumption equation and the canonical equation. When the real rate 
exceeds its equilibrium value, the level of output declines (iterate equation (21) forward), while the expected change in output must be positive. ${ }^{7}$

For their price specification McCallum and Nelson employ a Calvo-Rotemberg model justified by Rotemberg (1987)

$$
\Delta p_{t}=E_{t} \Delta p_{t+1}+\left(\theta / c_{1}\right) y_{t}
$$

Roberts (1995) derives an equation identical to (22), save for the inclusion of a time- $t$ disturbance in the right-hand side. Under the assumption of rational expectations, this specification also has counterintuitive dynamic implications: when output rises above potential, the level of inflation must increase, but the expected change in inflation must be negative. ${ }^{8}$ Again, these dynamics can only be satisfied if the inflation rate jumps immediately above its new, higher equilibrium level, and subsequently falls to it from above. This feature of the Calvo price model was pointed out in Fuhrer and Moore (1992), and for the Taylor (1980) contracting specification in Phelps (1978), Ball (1991), and Fuhrer and Moore (1995).

In a recent volume of the NBER Macroeconomics Annual, Rotemberg and Woodford (1997) present an optimizing model for monetary policy analysis which exhibits many of these same features. Their price specification is identical to equation (22) above. Their "IS" curve is (see pp. 312-15)

$$
E\left[R_{t+1}-\pi_{t+2}-\sigma\left(y_{t+1}-y_{t}\right)\right] \equiv \phi_{t}
$$

${ }^{7}$ Woodford (1996) arrives at a nearly identical formulation.

${ }^{8}$ The model in McCallum and Nelson (1998) predicts that the quasi-difference of inflation, $\pi_{t}-\beta E \pi_{t+1}$, must be expected to fall. For values of $\beta$ very near 1 , however, the dynamic implications are nearly the same. 
which can be rearranged to look exactly like equation (21) above, except for the dating of the expected real interest rate relative to the output terms. ${ }^{9}$

Finally, we note that a form of the well-known Lucas supply curve has the features of the basic model. Lucas (1972) writes the supply function as

$$
y_{t}=a\left(p_{t}-E_{t} p_{t+1}\right)+\eta_{t},
$$

where $y_{t}$ is the output gap in $\log$ form, $p_{t}$ is the log of the price level, $E_{t}$ indicates an expectation using information available at time $t, \eta_{t}$ is an error term which is unknown at time $t$ and $a>0$. This equation may be rewritten in the canonical form (6) by solving for $p_{t}$. The Lucas equation is analogous to Rotemberg's (1987), but with log prices instead of inflation.

\section{Modifications to the Basic Equation}

In this section, we consider the implications for the dynamic behavior of prices and output under some extensions to the canonical model of Section 2. In particular, we examine alterations in the expectations viewpoint date, the dating of the expectations variable, and the order of differencing imposed on prices or output. For concreteness, we look at explicit solutions when $x$ is $\mathrm{MA}(2)$ and consider the effects of changes in the dating of the expectations viewpoint or the expectations variable in explicit solutions. More generally, we look at the effect of these changes on the signs of the key correlations when $x$ is $\mathrm{MA}(\mathrm{q})$. These examples illustrate the range of possible effects of the dating changes in the context of a fairly general form for the driving variable $x$.

Thus, suppose that

$$
x_{t}=\epsilon_{t}+\alpha_{1} \epsilon_{t-1}+\alpha_{2} \epsilon_{t-2}
$$

${ }^{9}$ In their paper, the output terms are dated one period later, although output in period $t+1$ is predetermined in period t. To keep notation consistent throughout this paper, we simply shift the dating of output terms back one period to the date at which they are determined. In addition, Rotemberg and Woodford circumvent the counterfactual dynamic implications of their specification by allowing for shock processes with a richer stochastic structure. We do not explore that solution in this paper, preferring to examine the implications of the behavioral relationships for the dynamic evolution of key variables. 
and consider first the base case of equation (6). Then, by equation (13),

$$
z_{t}=\theta\left[\left(1+\alpha_{1}+\alpha_{2}\right) \epsilon_{t}+\left(\alpha_{1}+\alpha_{2}\right) \epsilon_{t-1}+\alpha_{2} \epsilon_{t-2}\right]
$$

Using (25), (26), and the first difference of (26), we find that

$$
\begin{gathered}
\operatorname{cov}\left(z_{t}, x_{t}\right) \geq \frac{2}{3} \theta \sigma_{\epsilon}^{2} \\
\operatorname{cov}\left(\Delta z_{t+1}, x_{t}\right) \leq-\theta \sigma_{\epsilon}^{2}
\end{gathered}
$$

illustrating the opposite signs of the correlations between $x$ and the level and change in $z$, respectively, which we obtained for a general MA process in Section 2.

Now assume that the date of the expectations variable is moved forward in equation (6):

$$
z_{t}=E_{t} z_{t+2}+\theta x_{t}
$$

Applying the same method as in Section 2, the solution is now

$$
z_{t}^{\prime}=\theta\left[\left(1+\alpha_{2}\right) \epsilon_{t}+\alpha_{1} \epsilon_{t-1}+\alpha_{2} \epsilon_{t-2}\right]
$$

which reflects the fact that the expectational variable is one period further into the future. We now obtain that

$$
\begin{gathered}
\operatorname{cov}\left(z_{t}^{\prime}, x_{t}\right) \geq \frac{3}{4} \theta \sigma_{\epsilon}^{2} \\
\operatorname{cov}\left(\Delta z_{t+1}^{\prime}, x_{t}\right) \leq-2 \theta \sigma_{\epsilon}^{2}
\end{gathered}
$$

Thus, even though the coefficients in (29) are ostensibly different from those in (26), the sign pattern of the covariances remains the same. Moreover, when $x$ is $\operatorname{MA}(\mathrm{q})$, 


$$
\begin{gathered}
\operatorname{cov}\left(z_{t}, x_{t}\right) \geq \frac{[q / 2]+2}{2[q / 2]+2} \theta \sigma_{\epsilon}^{2} \rightarrow\left\{\begin{array}{c}
\theta \sigma_{\epsilon}^{2} \text { as } q \rightarrow 0 \\
\frac{1}{2} \theta \sigma_{\epsilon}^{2} \text { as } q \rightarrow \infty
\end{array}\right. \\
\operatorname{cov}\left(\Delta z_{t+1}, x_{t}\right) \leq-\frac{q+2}{2 q+2} \theta \sigma_{\epsilon}^{2} \rightarrow\left\{\begin{array}{c}
-\theta \sigma_{\epsilon}^{2} \text { as } q \rightarrow 0 \\
-\frac{1}{2} \theta \sigma_{\epsilon}^{2} \text { as } q \rightarrow \infty
\end{array}\right.
\end{gathered}
$$

where $[\cdot]$ denotes truncation to an integer value.

Consider now a change in the viewpoint date for the expectation, first assuming that only the expectational term is affected:

$$
z_{t}=E_{t-1} z_{t+1}+\theta x_{t}
$$

As in the previous case, there is a two-period lag between the viewpoint date and the variable date, but both are moved back by one period. The solution is

$$
z_{t}^{\prime \prime}=\theta\left[\epsilon_{t}+\left(\alpha_{1}+\alpha_{2}\right) \epsilon_{t-1}+\alpha_{2} \epsilon_{t-2}\right]
$$

In this case, the covariances with $x$ are such that

$$
\begin{gathered}
\operatorname{cov}\left(z_{t}^{\prime \prime}, x_{t}\right) \geq \theta \sigma_{\epsilon}^{2} \\
\operatorname{cov}\left(\Delta z_{t+1}^{\prime \prime}, x_{t}\right) \leq-\frac{1}{2} \theta \sigma_{\epsilon}^{2}
\end{gathered}
$$

and the pattern is once again qualitatively the same. However, in this case, the results when $x$ is a general MA(q) process are not as clear-cut as in the previous cases. In the MA(q) case, we now obtain

$$
\begin{gathered}
\operatorname{cov}\left(z_{t}^{\prime \prime}, x_{t}\right) \geq \theta \sigma_{\epsilon}^{2} \\
\operatorname{cov}\left(\Delta z_{t+1}^{\prime \prime}, x_{t}\right) \leq\left(\frac{q}{4}-1\right) \theta \sigma_{\epsilon}^{2} \rightarrow\left\{\begin{array}{c}
-\theta \sigma_{\epsilon}^{2} \text { as } q \rightarrow 0 \\
\infty \text { as } q \rightarrow \infty
\end{array}\right.
\end{gathered}
$$


Thus, the signs of the two covariances are different for $0 \leq q \leq 4$, although the difference in sign is not guaranteed by the upper bound on the covariance of the change in $z$ when $q>4 .{ }^{10}$

Consider finally a case in which all the terms in the equation are subject to an earlier expectation viewpoint:

$$
E_{t-1}\left[z_{t}-z_{t+1}-\theta x_{t}\right]=0
$$

The solution is now

$$
z_{t}^{\prime \prime \prime}=\beta_{0} \epsilon_{t}+\theta\left[\left(\alpha_{1}+\alpha_{2}\right) \epsilon_{t-1}+\alpha_{2} \epsilon_{t-2}\right]
$$

This solution is qualitatively different from the others. By changing the viewpoint date for all variables, the leading coefficient of $\beta(L)$ remains undetermined, allowing an extra degree of freedom in the model. The corresponding covariance constraints are

$$
\begin{gathered}
\operatorname{cov}\left(z_{t}^{\prime \prime \prime}, x_{t}\right) \geq \beta_{0} \sigma_{\epsilon}^{2} \\
\operatorname{cov}\left(\Delta z_{t+1}^{\prime \prime \prime}, x_{t}\right) \leq\left(-\beta_{0}+\frac{1}{2} \theta\right) \sigma_{\epsilon}^{2}
\end{gathered}
$$

If $\beta_{0}>\frac{1}{2} \theta$, the signs of the covariances are the same as before. Smaller values of $\beta_{0}$ open up the possibility for covariances whose signs may be more in accord with empirical observations, though at the cost of a reduced informational content in the model in (6). Specifically, if we rewrite the expression for $z_{t}^{\prime \prime \prime}$ with a time $t$ viewpoint, as in equation (6), we obtain

$$
z_{t}^{\prime \prime \prime}=E_{t} z_{t+1}^{\prime \prime \prime}+\theta x_{t}+\lambda \epsilon_{t}
$$

${ }^{10}$ The solutions with a positive upper bound for the covariance of the change in $z$ do not seem typical of macroeconomic series. For example, the MA representation of the solution that corresponds to the upper bound has a positive weight on the current disturbance that is much smaller than the positive weights of other low-order lag terms. Moreover, the correlation between $x$ and the change in $z$ is always less than 0.19 and tends to zero as $q$ goes to infinity. 
where $\lambda=\beta_{0}-\theta\left(1+\alpha_{1}+\alpha_{2}\right)$. Thus, deviations from the solution of the base case of equation (6) imply the existence of an additional error term in the expression corresponding to (6). The systematic portion of the equation is insufficient, with a time $t$ viewpoint, to capture the exact relationship between $x$ and $z$. Predictably, the solution to the general MA(q) case is also undetermined by the model and is not explicitly presented here.

While the alterations discussed above leave the qualitative behavior of equation (6) in Section 2 generally unchanged, changing the order of differencing of $\mathrm{z}$ dramatically alters the equation's dynamic implications. Svensson (1997) considers forward-looking models for aggregate demand and inflation that begin with equations (21) and (22). However, Svensson assumes further that "costs of adjustment, overlapping contracts, or some other mechanism" alter the purely forward-looking specifications and augment them with backward-looking components. The resulting inflation and "IS" curves are

$$
\begin{aligned}
& \pi_{t+1}=\left(1-\alpha_{\pi}\right) E_{t-1} \pi_{t+2}+\alpha_{\pi} \pi_{t}+\alpha_{y} y_{t}+\epsilon_{t+1} \\
& y_{t+1}=\left(1-\beta_{y}\right) E_{t} y_{t+2}+\beta_{y} y_{t}-\beta_{r}\left(E_{t} R_{t+1}-E_{t} \pi_{t+2}\right)
\end{aligned}
$$

where $\left(1-\alpha_{\pi}\right)$ and $\left(1-\beta_{\mathrm{y}}\right)$ index the dependence on future inflation (output) in the inflation (IS) specification. ${ }^{11}$

This modification, while seemingly minor, has profound implications for the dynamics of inflation and output. When $\alpha_{\pi}=.5$, we can rewrite the inflation equation as (ignoring expectation viewpoint dates for the moment)

$$
\left(\pi_{t+2}-\pi_{t+1}\right)-\left(\pi_{t+1}-\pi_{t}\right)=-2\left(\alpha_{y} y_{t}+\epsilon_{t+1}\right)
$$

Now the second difference in inflation is negatively related to the output gap. In this specification, both the level and first difference of inflation will be positively correlated with the output gap,

\footnotetext{
${ }^{11}$ Svensson notes further that this IS curve can be derived from a model of consumption with non-time-separable preferences. Fuhrer (1998) pursues this avenue in more detail.
} 
while the second difference will be negatively correlated. ${ }^{12}$ The dynamic response to a positive output gap is as follows: (1) The level of inflation will be higher; (2) the higher level will now arise through a series of positive changes in the rate of inflation, as opposed to a one-time jump and a series of negative changes in the Calvo-Rotemberg model; and (3) because the seconddifference in inflation is negatively related to output, the change in inflation will now jump to a higher level and decline over time. In essence, the "jump" behavior (or, in the presence of interestrate smoothing or other inertia, "overshooting") in the Calvo-Rotemberg specification has been displaced from the level to the change in inflation. Of course, an identical argument holds for the forward/backward IS curve in equations (40).

Svensson's (1997) modification to the basic model does not contain an explicit behavioral model of the adjustment pattern in equations (40). One behavioral alteration to the standard dynamic rational expectations models that rectifies the perverse dynamics documented above is habit formation. Habit formation assumes a utility function for which the standard consumptionsmoothing motive applies to both the change and the level of consumption. As a result, the response of consumption to income or real interest rate shocks is smoother and more humpshaped than that of the conventional life-cycle/permanent-income model. Habit formation has been analyzed in detail in Carroll, Overland, and Weil (1995), Campbell and Cochrane (1994), and Fuhrer (1998).

Consider a simple example of habit-formation in which the utility function for the representative consumer is

$$
U\left(C_{t}\right)=\frac{1}{1-\sigma}\left[\frac{C_{t}}{C_{t-1}^{\gamma}}\right]^{1-\sigma}=\frac{1}{1-\sigma}\left[\frac{C_{t}}{C_{t-1}} C_{t-1}^{1-\gamma}\right]^{1-\sigma}
$$

In this utility function, the "reference level" of consumption is last period's consumption, and the importance of habit formation (which is the same as the importance of the reference level) is indexed by the exponent $\gamma$. The re-expression of the utility function in the right-hand panel of the

\footnotetext{
${ }^{12}$ While this argument has been demonstrated for $\alpha_{\pi}=.5$, the qualitative effect on the model's dynamics will be the same as long as $0<\alpha_{\pi} \leq 1$.
} 
equation makes it clear that utility depends on both the level and the change in consumption, and thus consumers will wish to smooth both the change and the level of consumption in response to shocks.

The solution to this model is complicated and, in general, it is difficult to sign the types of correlations on which we have been focusing, in this case between income and the level and change in consumption. ${ }^{13}$ However, we can use numerical simulations to suggest that this type of model can avoid the counterfactual implications of the basic model. Figure 7 compares the response to a persistent real income shock of a simple dynamic monetary rational expectations model with habit formation to a model with standard life-cycle/PIH consumers. ${ }^{14}$ As the figure shows, the response of consumption under habit formation is hump-shaped and smoother, in contrast to the immediate adjustment of consumption in the LC/PIH model. In addition, note that the initial co-movement between both the level and change in consumption and the positive income shock is positive in the beginning of the habit-formation simulation, whereas in the $\mathrm{LC} / \mathrm{PIH}$ model the initial co-movement of the level of consumption with the income shock is positive, but the co-movement between the change in consumption and the positive income shock is always negative. ${ }^{15}$

\section{Interest Rate Smoothing and Model Dynamics}

${ }^{13}$ The model is taken from the linearized habit-formation model in Fuhrer (1998), using the estimates of the utility parameters $\sigma$ and $\gamma$ presented in that paper. The deviation of real income from its long-run trend evolves according to a first-order autoregressive process with autoregressive coefficient 0.9 .

${ }^{14}$ In addition to the first-order conditions for the consumer's problem the model uses a first-order autoregressive process for the deviation of output around trend, and a simple feedback rule for the real interest rate that makes the real interest rate and output positively correlated. The latter relation mimics in reduced form a monetary policy response to demand shocks.

${ }^{15}$ Fuhrer (1998) provides evidence for the habit formation model of the type displayed in Section 1 . The success of the habit formation model is qualitatively similar to that for the Rudebusch-Svensson model above: the vector autocovariance function and impulse responses for the habit formation model match those of the unconstrained VAR much more closely than the standard consumption model. 
In the empirical modeling of Section 1, we employ a data-consistent federal funds rate reaction function. This reaction function includes a considerable degree of "interest rate smoothing," or less cryptically, a sizable coefficient on the lagged funds rate. This section will show that, for the McCallum-Nelson specification (and the like), interest rate smoothing provides the only source of persistence in the model. Without interest rate smoothing, the model has trivial dynamics: when perturbed by a shock, the economy returns immediately to its steady state.

To illustrate this point, we use the IS curve of equation (21) and the price specification of equation (22), and a simple reaction function of the form

$$
i_{t}=s i_{t-1}+(1-s) \bar{\pi}+.5\left(\pi_{t}-\bar{\pi}\right)+.5 y_{t}
$$

where $i_{t}$ is the nominal interest rate, $s$ is a parameter that governs the degree of interest rate smoothing, the bar over $\pi$ indicates its target level, and the coefficients are chosen as in Taylor (1993). The equilibrium real interest rate is assumed to be zero.

The simulation that we use is an announced, credible disinflation that is accomplished by a decrease in the inflation target from 3 percentage points in period 0 to zero in period 1 . The model begins at its steady-state (all nominal variables at 3 percent, the output gap at 0 ). Figure 8 displays the response of the specification that comprises equations (21), (22), and the reaction function (43) with $s=0$. The response of inflation to real output in equation (22) is set as in Section 1 , and $\sigma$, the sensitivity of real output to the real interest rate in equation (21), is 0.8 , consistent with a modest intertemporal elasticity of substitution. ${ }^{16}$ As the figure indicates, with no lags in any of the model's equations, the response of the system to the new inflation target is immediate: inflation and the nominal interest rate jump from their old steady-state values of 0.03

${ }^{16}$ Rotemberg and Woodford estimate $\sigma$ to be 0.16 , which as they note implies a very large intertemporal elasticity of substitution. The qualitative features of the results displayed here are not sensitive to variations in $\sigma$. 
to their new steady-state values of 0 . The output gap remains at zero throughout. The model has no dynamics at all. ${ }^{17}$

Note that changing the expectations viewpoint date for future output to t- 1 in the IS equation does not change the model responses at all. Absent a shock in the current period, which by definition could not be anticipated last period, output next period is expected to be at its steady state value of zero. When the disinflationary shock hits, because there is no source of persistence in the model, the expectation for output in the next period is still zero, regardless of the viewpoint date. Even when the model is disrupted by a sequence of iid shocks, the expectation for output in the next period will always be zero, because it is only the unanticipated shocks that keep output from its steady state, and then only for a single period. ${ }^{18}$

In addition, moving the date of the expectational variable in the IS curve from $t+1$ to $t+2$ has very little impact on the simulated values for this disinflationary shock, with or without interest rate smoothing. Output and inflation still jump in response to the shock; their levels and differences have opposite-signed correlations with real interest rates or output.

Figure 9 shows the response of the same model to the same disinflation shock, but with interest rate smoothing $(s=0.9)$. In this case, output and inflation still jump, but in the presence of an inertial nominal rate, inflation overshoots its new steady-state value, and then rises to it from below. This dynamic is analogous to the overshooting behavior of the exchange rate in a model with sticky prices, as first shown in Dornbusch (1976). The responses in this figure look much more like the impulse responses in Figure 4 in Section 1. But it is only interest rate smoothing that keeps the model from looking like Figure 3.

These simulations raise a question about the internal consistency of the empiricallyconsistent reaction function and the McCallum-Nelson-type specifications. If the economy can

${ }^{17}$ If the expectation terms in equations (21) and (22) are replaced by lags of $y$ and $\Delta \pi$, respectively, but the assumption of rational expectations is retained, the model with $\mathrm{s}=0$ in (43) is unstable. With $\mathrm{s}>0.5$, however, the model converges. A model with these properties is explored in Estrella (1997).

${ }^{18}$ Of course, shocks that are known by agents in the model to be serially correlated will impart persistence to the movements in output and inflation. 
jump immediately to its long-run equilibrium, why would the monetary authority behave so inertially? Does the monetary authority unnecessarily respond in a sluggish fashion to deviations of output and inflation from their targets?

\section{Conclusions}

Empirical economic modeling is widely acknowledged to be guided by two important objectives. First, it is desirable that empirical models be derived from sound economic principles by assuming that agents optimize. The more unsubstantiated assumptions a model contains, the less compelling its implications will be. A second objective, however, is consistency with the data. A model derived flawlessly from careful introspection can be nevertheless deemed implausible if its empirical implications fail to match those of the available data.

We argue in this paper that various recent macroeconomic models based on sound microeconomic foundations fare poorly when confronted with the data. We show that those models share some basic features: they assume that expectations are rational, they include expectations terms explicitly, and they tend to imply that the level and change in a given variable have correlations of opposite signs with the level of a second variable. Generally, the only way to make such correlations consistent with the data is to assume that at least one of the variables jumps in ways that are unsupported by empirical evidence.

Through our choice of examples, we demonstrate that these properties are relatively pervasive in the macroeconomics literature. They are found in various standard models that are widely used for both macroeconomic research and policy analysis. Furthermore, since monetary policy is generally assumed to affect real variables only in the short run, the failure of these models to capture the short-term dynamics of variables such as inflation and output make their frequent use in policy analysis particularly problematic.

Our principal conclusion is that the inclusion of explicit expectations in macroeconomic models does not suffice to insure that the models are empirically suitable and in fact may be counterproductive, even if the model is derived from optimizing principles. Through general analysis and specific examples, we demonstrate that the counterfactual properties of these models 
are quite robust. For example, simple changes in the dating of variables or expectations will not change the basic properties of the models. Thus, easy fixes seem to be unavailable.

On the positive side, however, we also suggest that these types of models may be more consistent with the data if they are written in backward-looking form (without explicit expectations) or in terms of higher-order differences of the variables. For instance, a model of inflation that does not perform well empirically might be improved by using a similar model based on the second difference of inflation. Svensson (1997) is an example of the application of this technique. We also present evidence that simple alterations to the utility function assumed in the consumer's problem to reflect habit formation can circumvent the problem. 


\section{References}

Anderson, Gary and George Moore, 1985. “A Linear Algebraic Procedure for Solving Linear Perfect Foresight Models,” Economics Letters, 17, pp. 247-252.

Ball, Laurence, 1991. "The genesis of inflation and the costs of disinflation," Journal of Money, Credit, and Banking, 23, pp. 439-461.

Blanchard, Olivier and Charles Kahn, 1980. "The Solution of Linear Difference Models Under Rational Expectations," Econometrica, 48, pp. 1305-11.

Campbell, John Y. and John Cochrane, 1994. "By Force of Habit: A Consumption-Based Explanation of Aggregate Stock Market Behavior," Working Paper, prepared for the NBER Economic Fluctuations Research Meeting, October 28, 1994, September.

Campbell, John Y. and N. Gregory Mankiw, 1991. "Consumption, Income, and Interest Rates: Reinterpreting the Time Series Evidence," NBER Macroeconomics Annual, O. Blanchard and S. Fischer, editors, pp. 185-216.

Carroll, Christopher D. and Overland, Jody and David N. Weil, 1995, "Saving and Growth with Habit Formation," Finance and Economics Discussion Series Working Paper \#95-42, September.

Christiano, Lawrence J., Eichenbaum, Martin and Charles Evans, 1994. "Identification and the Effects of Monetary Policy Shocks," Working Paper, May.

Clarida, Richard, Jordi Gali and Mark Gertler, 1997. "The Science of Monetary Policy," Manuscript, September (Forthcoming Journal of Economic Literature). 
Davidson, Russell and James G. MacKinnon, 1993. Estimation and Inference in Econometrics, Oxford: Oxford University Press.

Dornbusch, Rudiger, 1976. "Expectations and Exchange Rate Dynamics," Journal of Political Economy, 84, pp. 1161-76.

Estrella, Arturo, 1997. "Why Do Interest Rates Predict Macro Outcomes? A Unified Theory of Inflation, Output, Interest and Policy,” Federal Reserve Bank of New York Research Paper \#9717.

Fuhrer, Jeffrey C. 1998. “An Optimizing Model for Monetary Policy Analysis: Can Habit Formation Help?” Federal Reserve Bank of Boston Working Paper 1998-01.

Fuhrer, Jeffrey C. and George R. Moore. 1992. "Monetary Policy Rules and the Indicator Properties of Asset Prices," Journal of Monetary Economics, 29, 303-336.

Fuhrer, Jeffrey C. and George R. Moore. 1995. "Inflation Persistence,” Quarterly Journal of Economics, 110, Feb. 127-159.

Leeper, Eric and Sims, Christopher and Tao Zha, 1996. "What Does Monetary Policy Do?," Brookings Papers on Economic Activity, 2, pp. 1-78.

Lucas, Robert E. 1972. "Econometric Testing of the Natural Rate Hypothesis," in O. Eckstein, ed., The Econometrics of Price Determination Conference, Board of Governors of the Federal Reserve System, Washington, D.C.

Lucas, Robert E. 1976. "Econometric Policy Evaluation: A Critique," Carnegie-Rochester Conference Series on Public Policy, 7-33. 
Mankiw, N. Gregory, 1985. “Consumer Durables and the Real Interest Rate,” Review of Economics and Statistics, 67 No. 3, August, pp. 353-362.

McCallum, Bennett T. and Edward Nelson, 1998, "Operational Policy Rules in an Optimizing ISLM Model,” prepared for the joint CEPR/San Francisco Fed conference.

Phelps, Edmund S., 1978. "Disinflation without Recession: Adaptive Guideposts and Monetary Policy," Weltwirtschaftliches Archiv, 100, 239-265.

Roberts, John. 1995. "New Keynesian Economics and the Phillips Curve," Journal of Money, Credit, and Banking, 37:(4), 975-984.

Rotemberg, Julio, 1987. "The New Keynesian Microfoundations," in Stanley Fischer (ed.), NBER Macroeconomics Annual 1987. Cambridge, MA: MIT Press, 69-104.

Rotemberg, Julio and Michael Woodford, 1997. “An Optimizing Model for Monetary Policy Analysis,” NBER Macroeconomics Annual, B. Bernanke and J. Rotemberg, eds., 297-346.

Rudebusch, Glenn and Lars E.O. Svensson, 1998. "Policy Rules for Inflation Targeting," NBER Working Paper No. 6512 (Forthcoming in John B. Taylor, ed., Monetary Policy Rules, Chicago: University of Chicago Press).

Svensson, Lars E. O., 1997. "Inflation Targeting: Some Extensions," IIES Seminar Paper No. 625, February 1997 (NBER Working Paper No. 5962).

Taylor, John B., 1980, “Aggregate Dynamics and Staggered Contracts,” Journal of Political Economy, 88, 1-23. 
Whiteman, Charles H., 1983. Linear Rational Expectations Models: A User's Guide, Minneapolis: University of Minnesota Press.

Woodford, Michael, 1996. "Control of the Public Debt: A Requirement for Price Stability," NBER Working Paper No. 5684. 
Figure 1

Vector autocorrelation Function for McCallum-Nelson Model Hours-based output gap (McCallum-Nelson)

Inflation, lagged Inflation
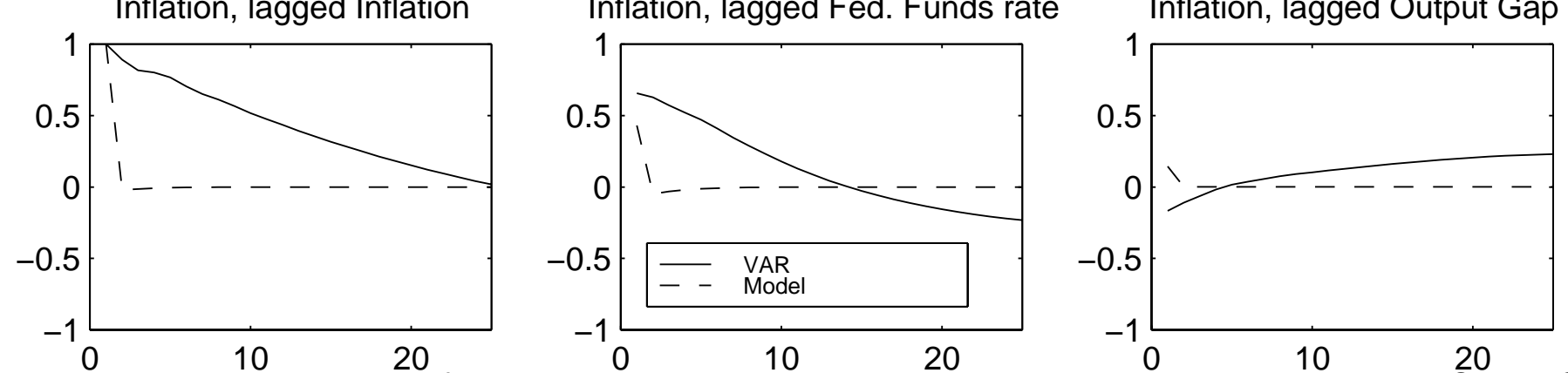

Fed. Funds rate, lagged InflationFed. Funds rate, lagged Fed. Funds raÆed. Funds rate, lagged OOutput Gap
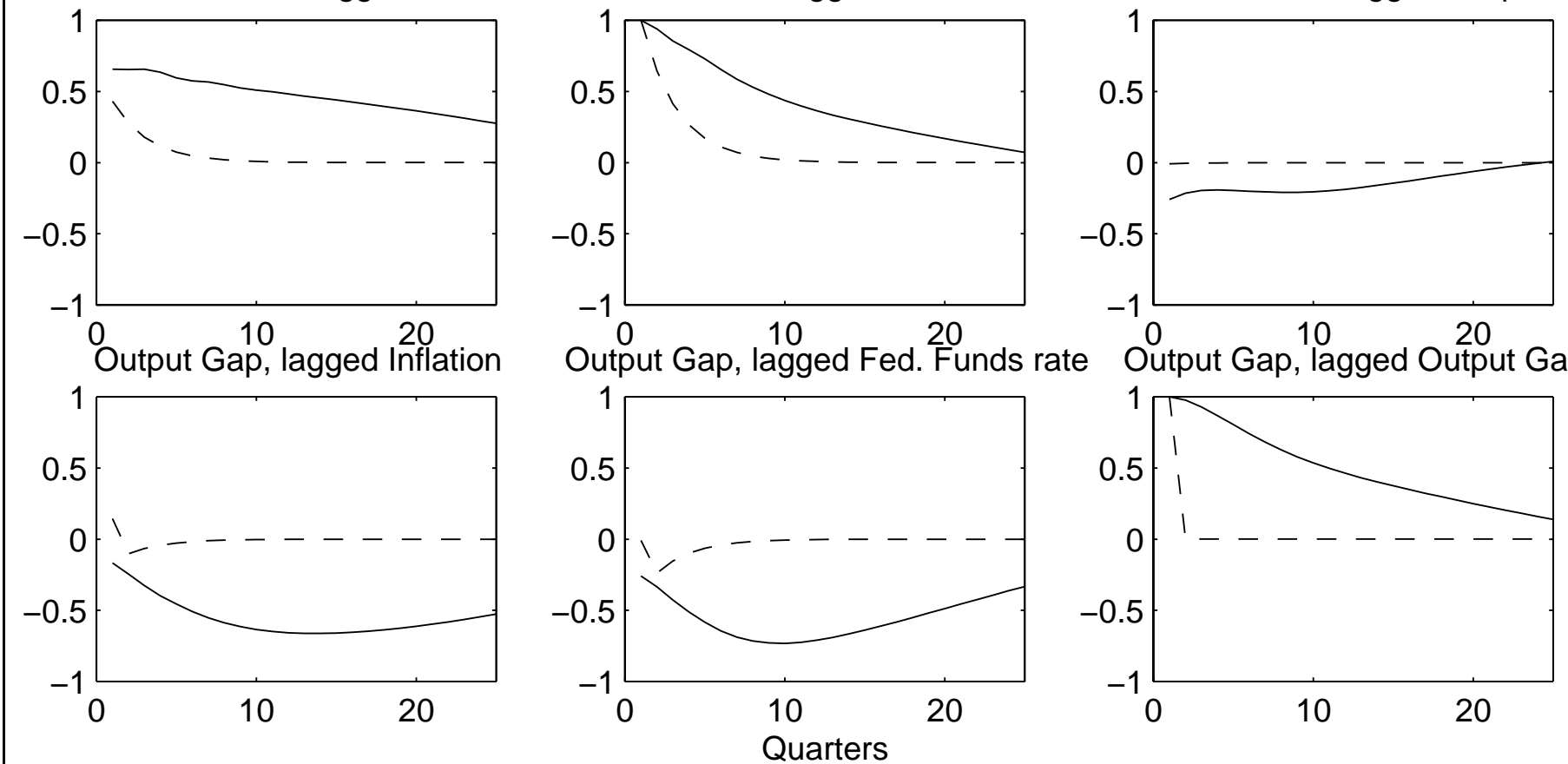
Figure 2

Vector autocorrelation Function for Rudebusch-Svensson Model Hours-based output gap (McCallum-Nelson)

Inflation, lagged Inflation
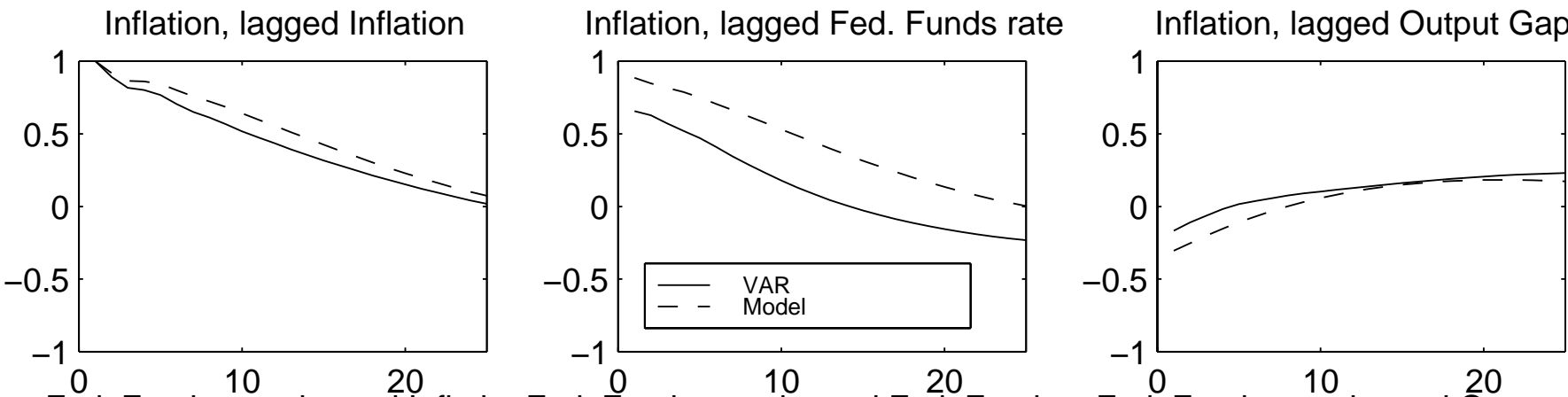

Fed. Funds rate, lagged InflationFed.
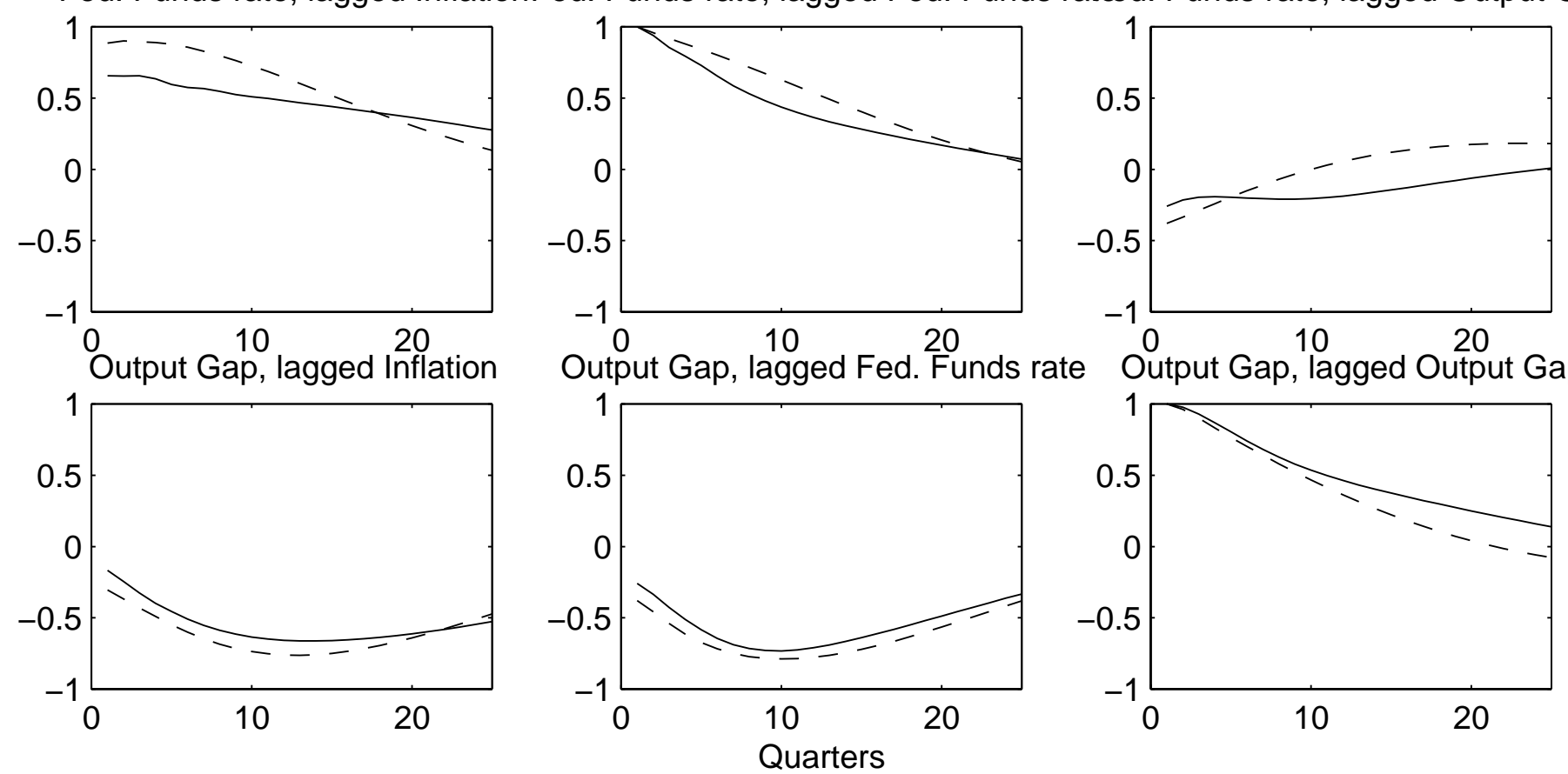


\section{Figure 3}

\section{Impulse responses for McCallum-Nelson Model Hours-based output gap}
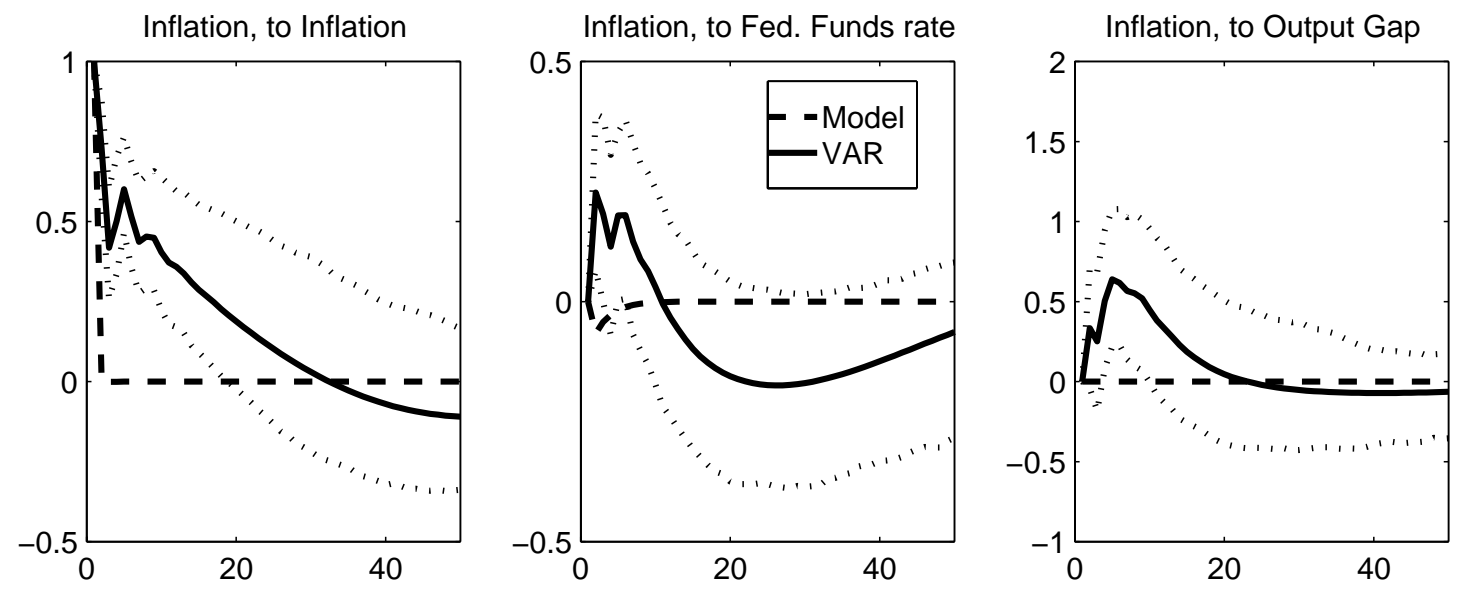

Fed. Funds rate, to Inflation

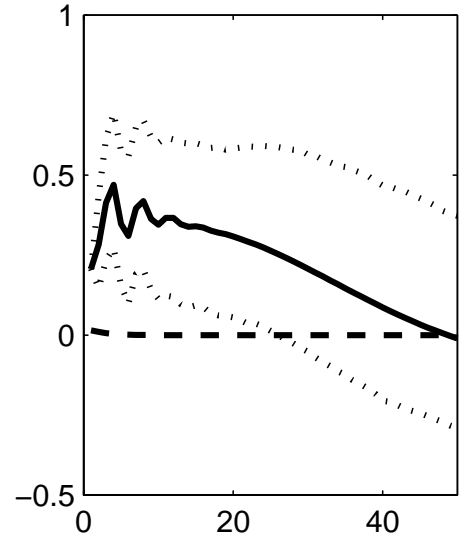

Fed. Funds rate, to Fed. Funds rate

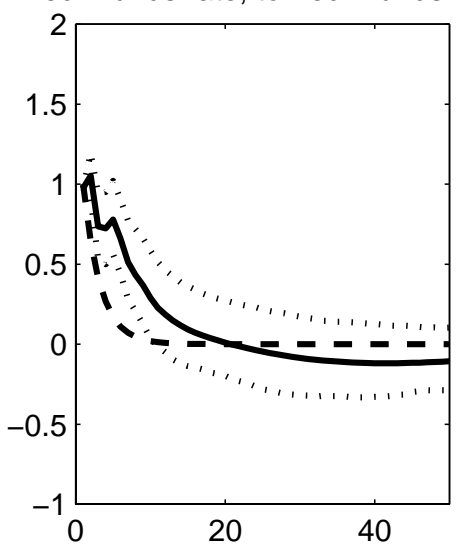

Fed. Funds rate, to Output Gap
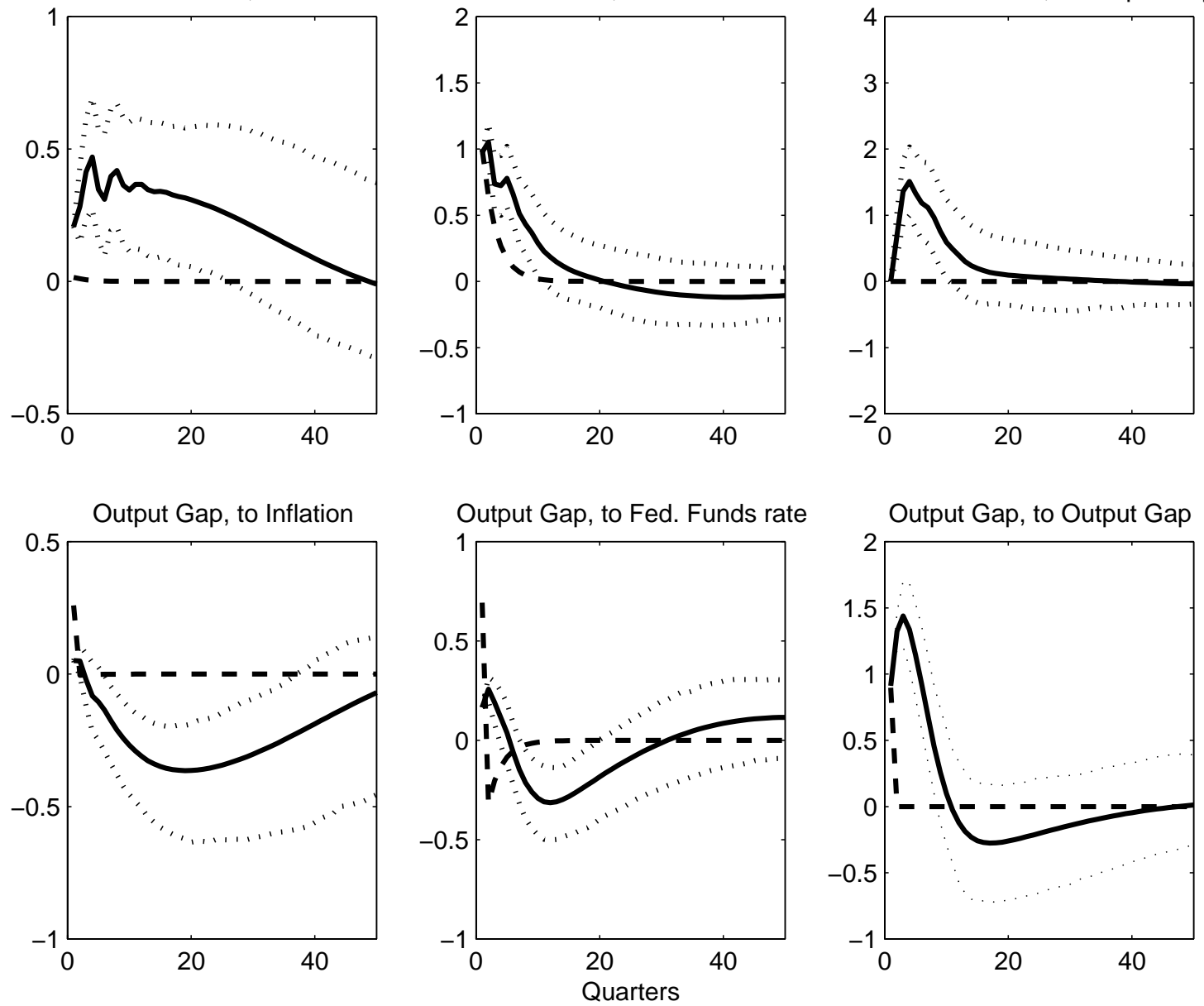

Dotted lines represent $90 \%$ confidence intervals 
Figure 4

Impulse responses for Rudebusch-Svensson Model Hours-based output gap
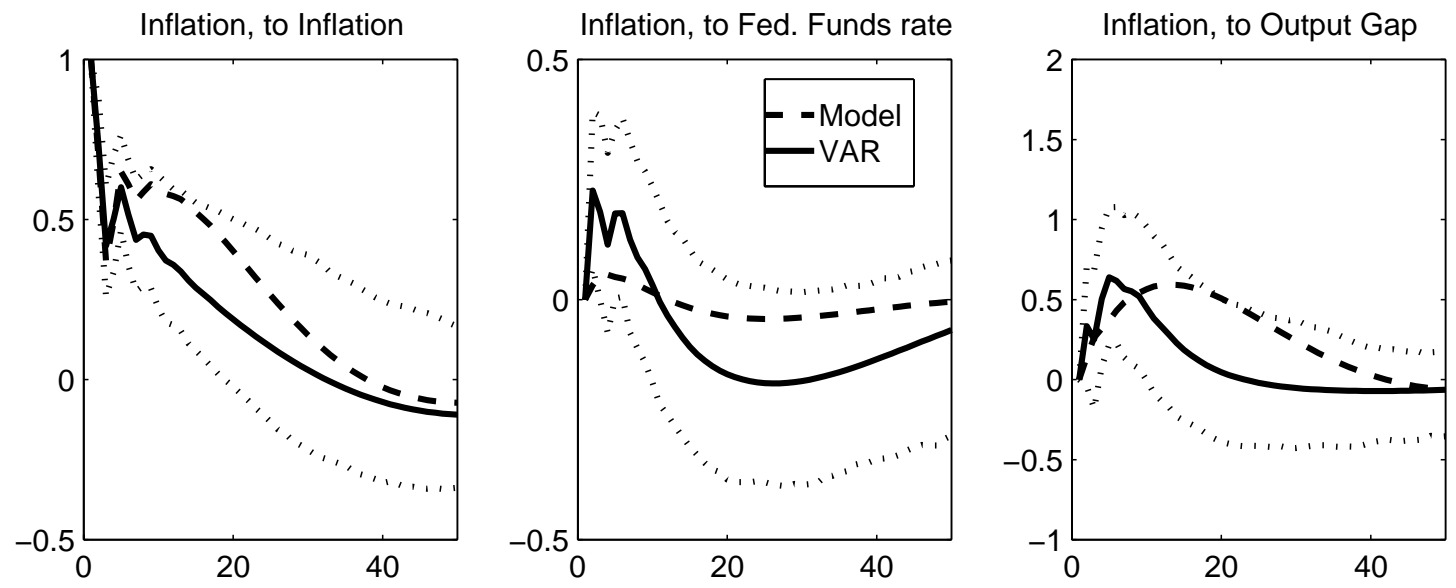

Fed. Funds rate, to Inflation

Fed. Funds rate, to Fed. Funds rate

Fed. Funds rate, to Output Gap
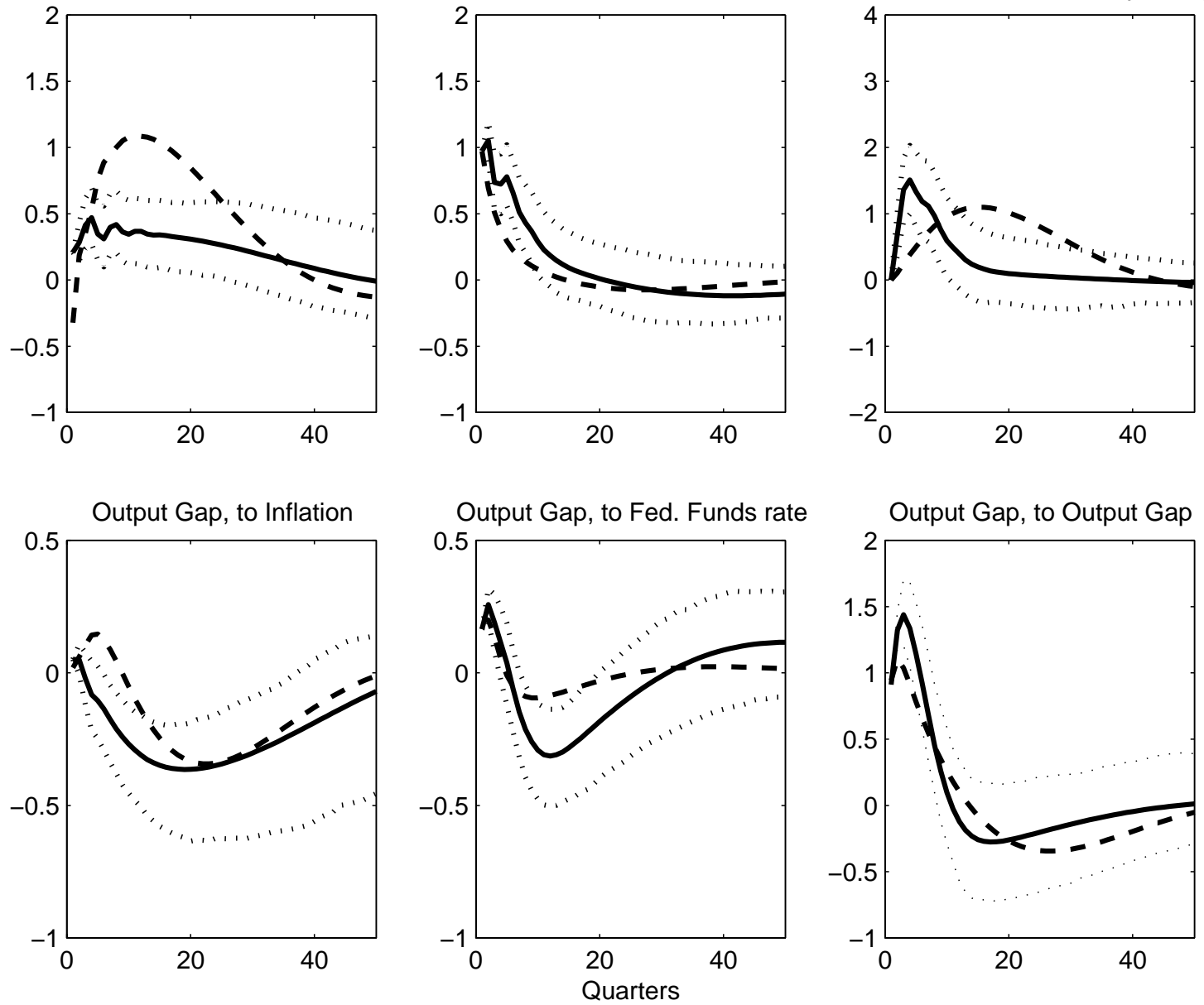

Dotted lines represent $90 \%$ confidence intervals 
Figure 5

\section{Vector autocorrelation Function for McCallum-Nelson Model} Models re-estimated on H-P output gap

Inflation, lagged Inflation

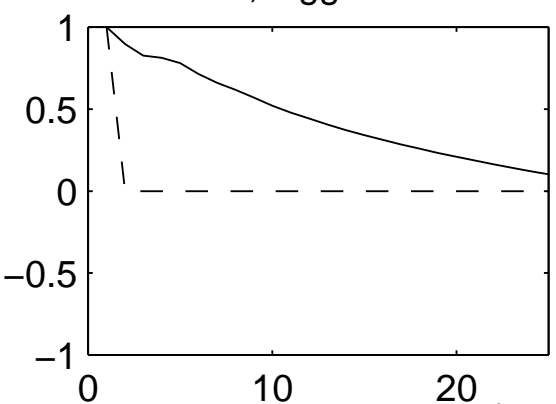

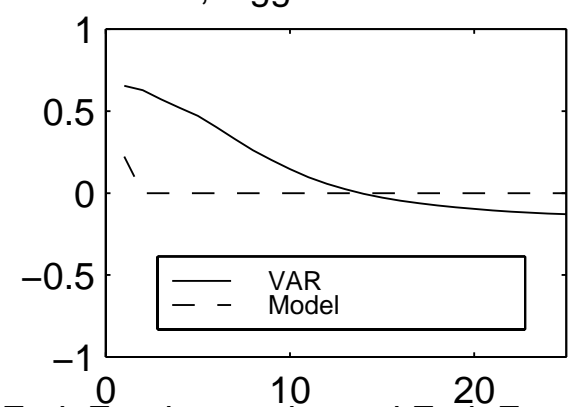

Inflation, lagged Output Gap

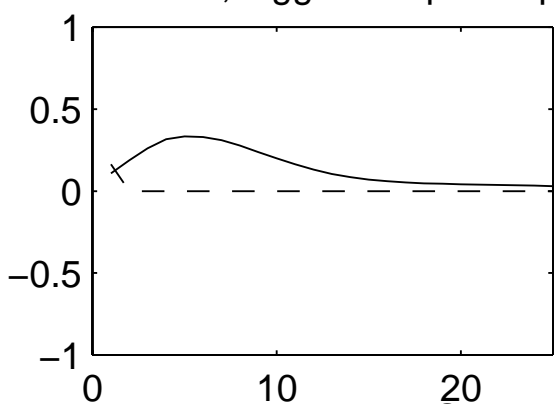

Fed. Funds rate, lagged InflationFed. Funds rate, lagged Fed. Funds raÆed. Funds rate, lagged Output Gap
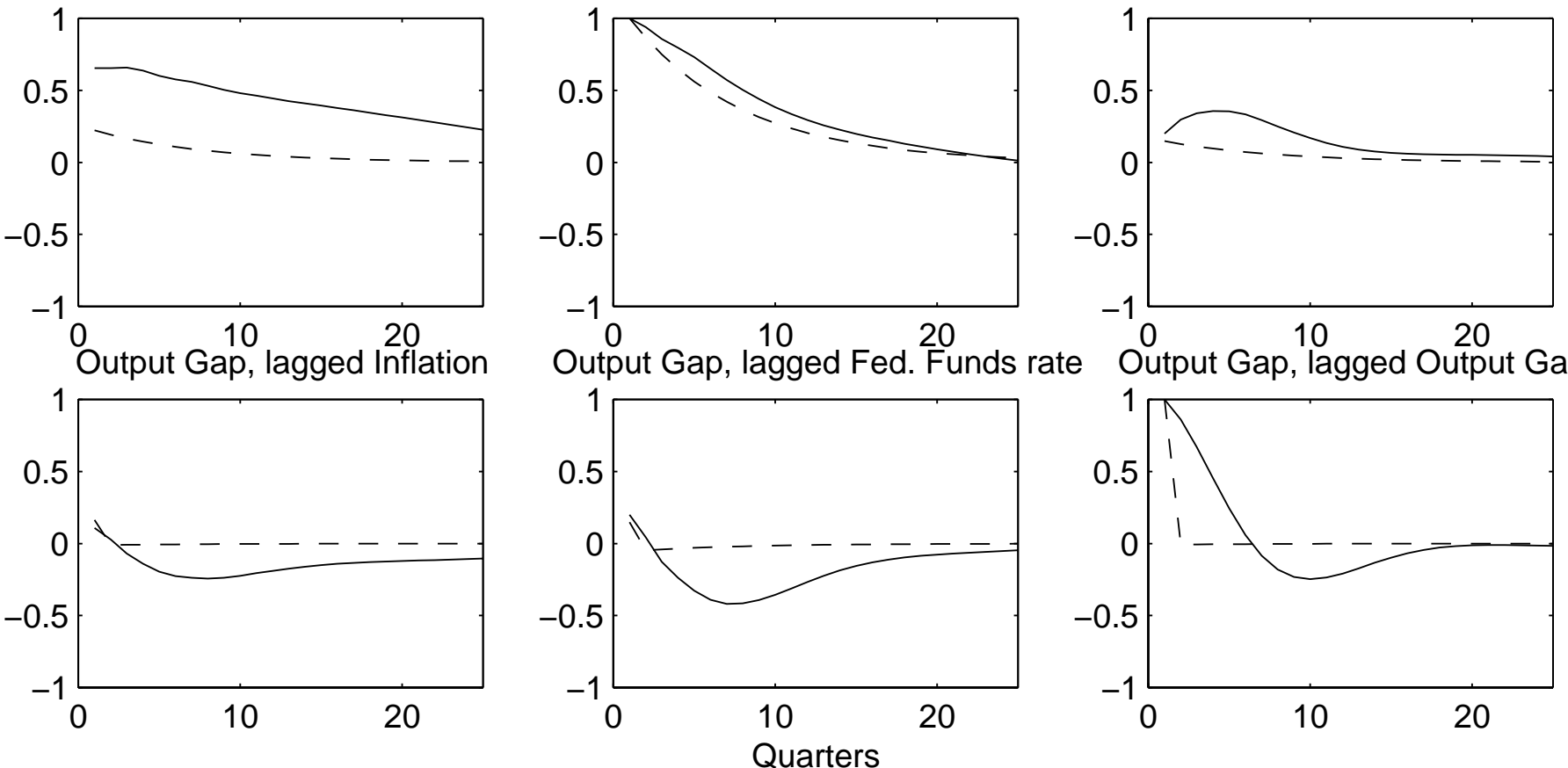
Figure 6

Vector autocorrelation Function for Rudebusch-Svensson Model Models re-estimated on H-P output gap

Inflation, lagged Inflation

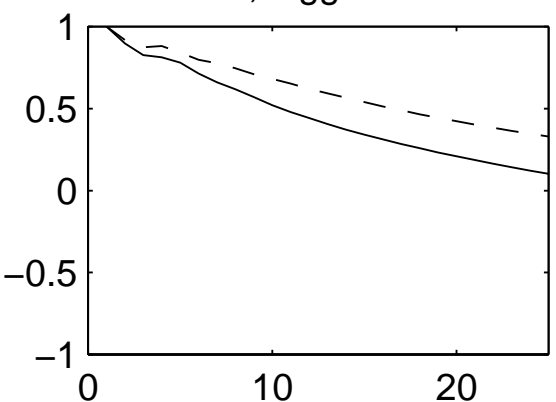

Inflation, lagged Fed. Funds rate
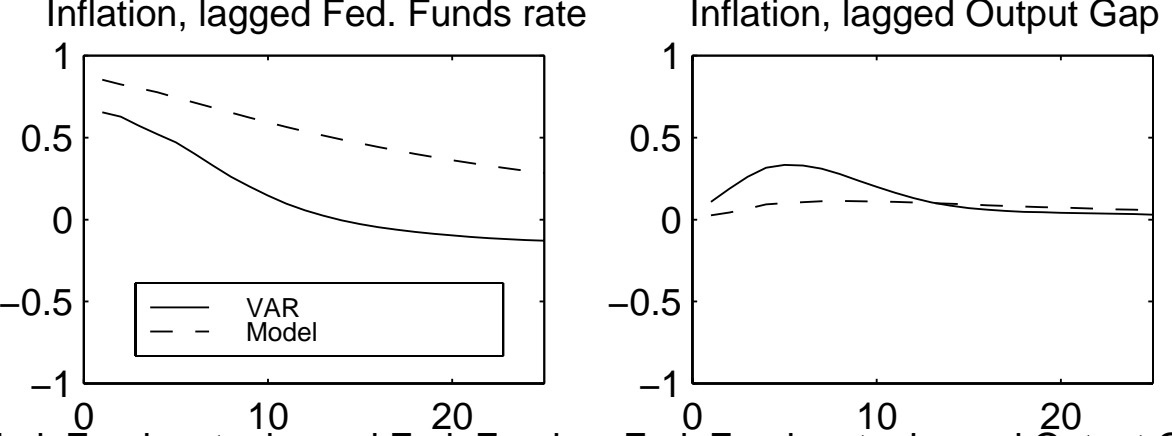

Fed. Funds rate, lagged InflationFed. Funds rate, lagged Fed. Funds raFed. Funds rate, lagged Output Gap
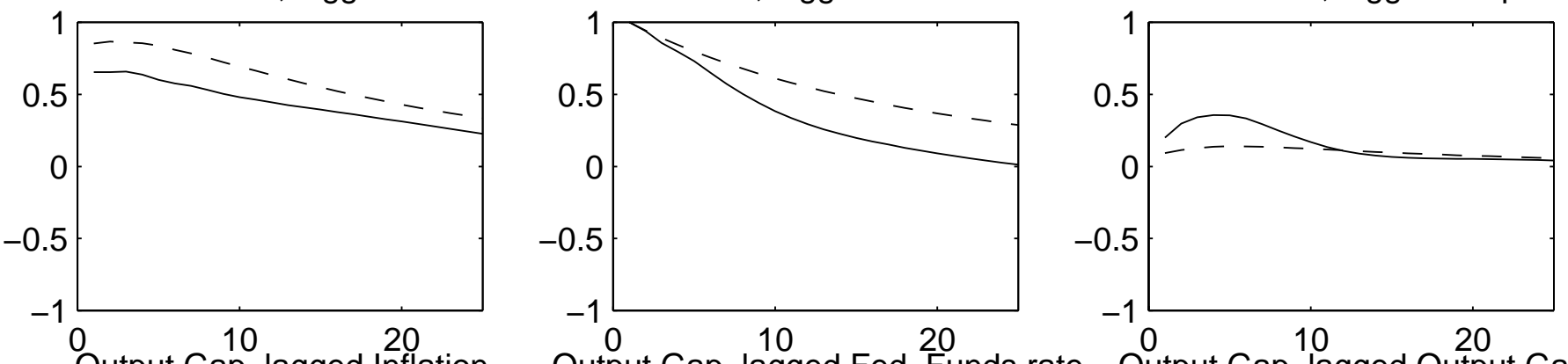

Output Gap, lagged Fed. Funds rate Output Gap, lagged Output Gap
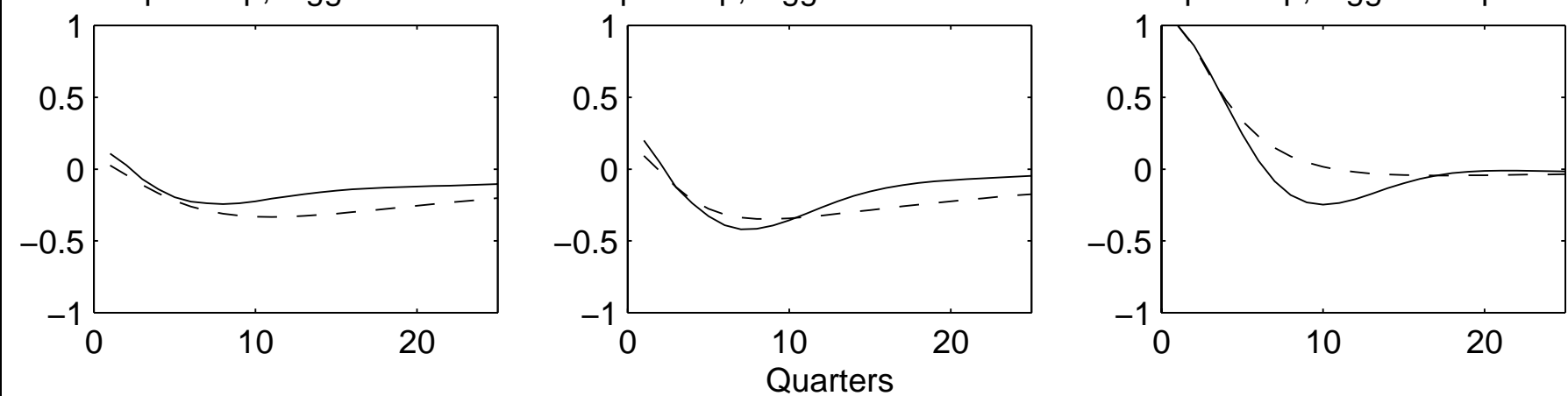


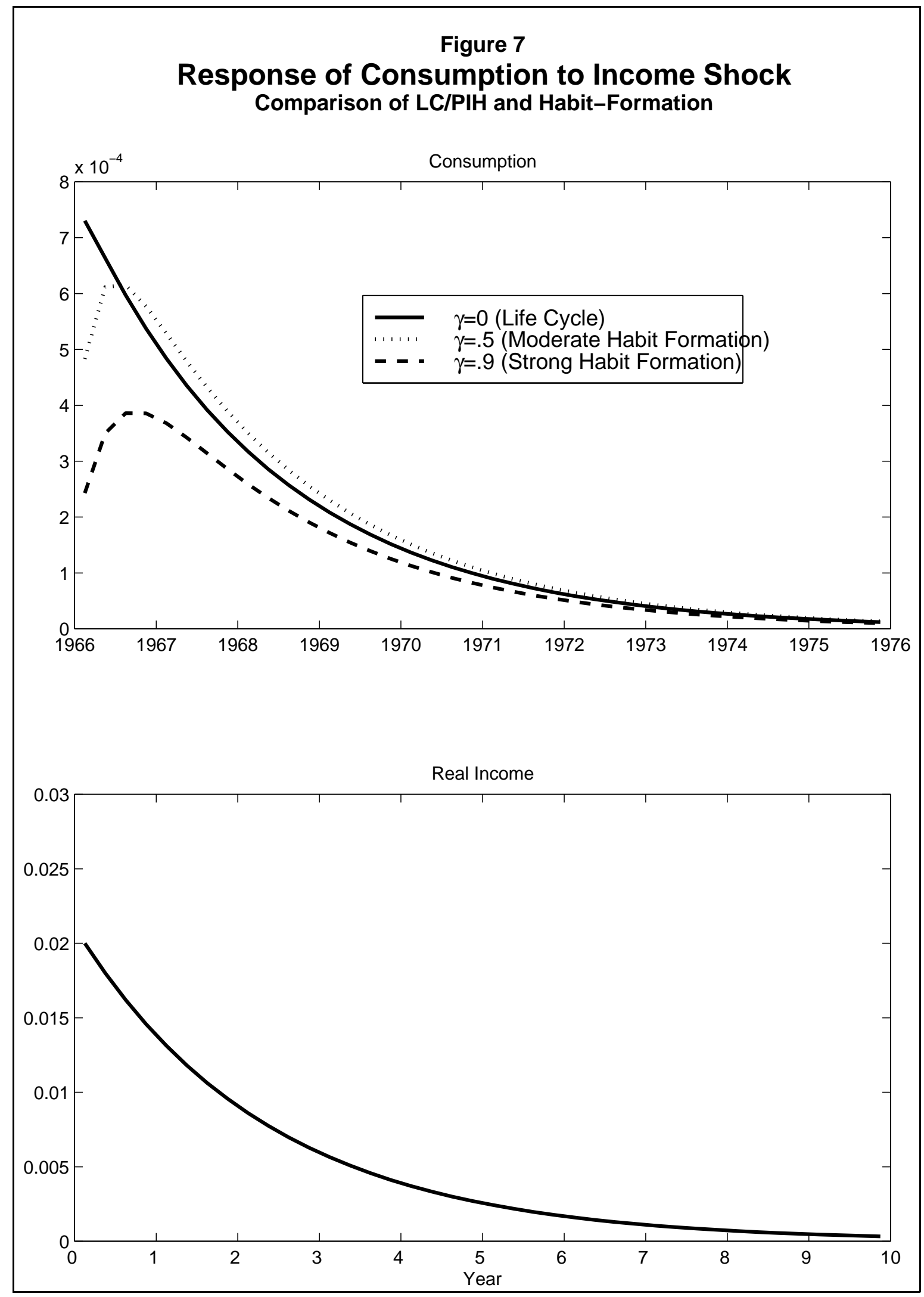


Figure 8

McCallum-Nelson model, no Interest Rate Smoothing (s=0)
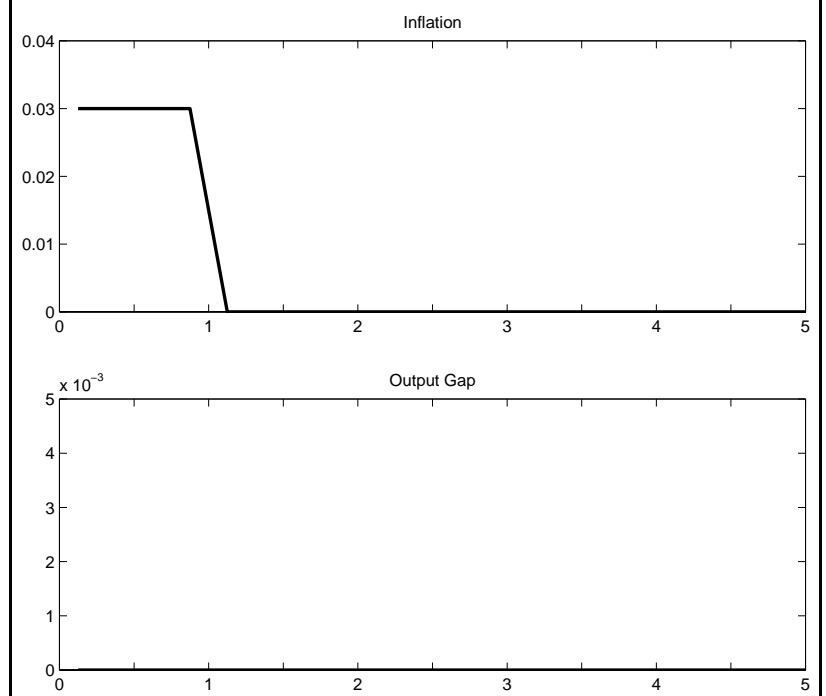

Nominal rate

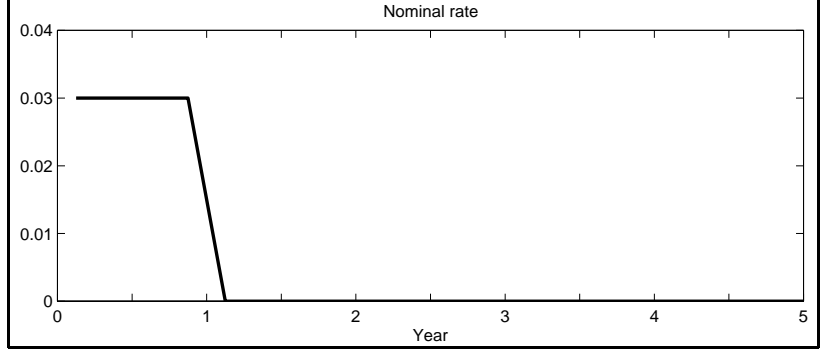




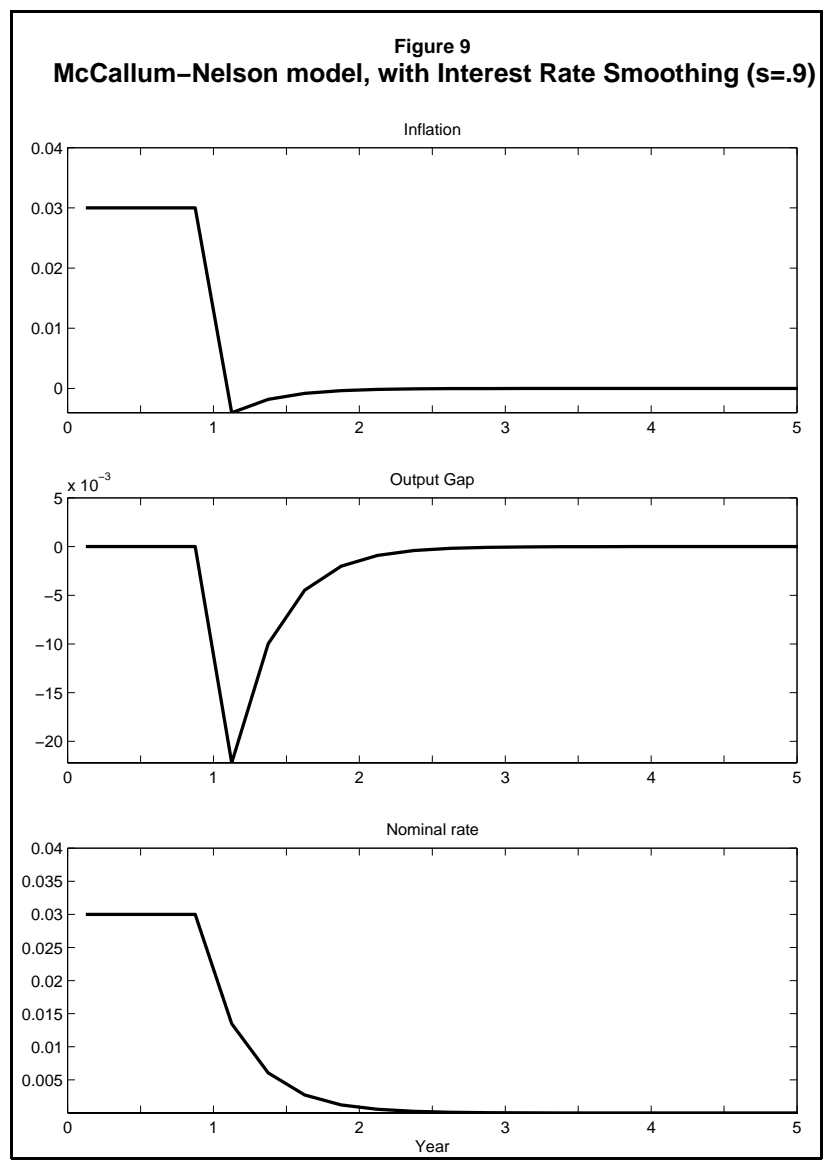

